\title{
A crucial review on recent updates of oxidation behavior in high entropy alloys
}

\author{
Bhargavi Rani Anne ${ }^{1}$ (1) $\cdot$ Shajahan Shaik ${ }^{4}$ Masaki Tanaka ${ }^{1,3} \cdot$ Anindya Basu $^{2}$
}

Received: 24 November 2020 / Accepted: 12 February 2021 / Published online: 23 February 2021

(C) The Author(s) 2021 OPEN

\begin{abstract}
Recently, High entropy alloys (HEAs) advanced into high-temperature applications as potential candidates by enduring high temperatures with high thermal stability, higher oxidation and corrosion resistances, thermal fatigue, and creep resistances. HEAs acquire unique characteristics called core effects of HEAs: high entropy effect, sluggish diffusion effect, severe lattice distortion, and cocktail effect. HEAs frequently exhibit remarkable properties because of having such unique core effects. Thus, the emergence of HEAs has gained significant interest in the field of materials leading to a contemporary point of discussion on their exciting nature and properties. The current review article intends to summarize the significant works on the oxidation behavior of High entropy alloys (HEAs). Also, peculiar attention has been invested in comprehending oxidation behavior of HEAs in the viewpoint of the crystal structure that is BCC-HEAs, FCC-HEAs and few case studies were compared with the conventional alloys. Current challenges and essential future directions in this field are also pointed out.
\end{abstract}

Keywords High entropy alloys · Oxidation behavior · High-temperature applications · Microstructure · Oxidation kinetics

\section{Introduction}

Ever since the Bronze age, alloying has been persistently emerging with many progressions. Recently, improving novel alloys that contain multi-elements became a contemporary research topic to meet the requirements of advanced applications that demands higher performances. Conventional alloys consist primarily of one or two principal elements chosen to meet the demand of specific property for a specific application, while other alloying additions to those systems further enhance their properties. On the other hand, High-entropy alloys (HEAs) which have a new concept of alloy design that contains five or more principal elements where each element mixed in equimolar ratio or near equimolar, for instance, AICoCrFeMnNi [1], and FeCrMnNiCo [2]. Though K. F. Achard had investigated the first multi-component system with five to seven principal elements in the 18th century [3], it took almost two centuries for the notable reception on the HEAs research after Yeh et al. [2] and Cantor et al. [4] in 2004. Later, a detailed study on non-equiatomic multicomponent materials such as $\mathrm{Fe}_{40} \mathrm{Mn}_{40} \mathrm{Co}_{10} \mathrm{Cr}_{10}$ [5], have been widely reported.

The unique attribute of HEA that distinguishes from conventional alloys is, HEAs mostly comprises a simple solid solution instead of forming complex phases or intermetallic compounds, which is fundamentally due to high mixing entropies and sluggish diffusion that further

Bhargavi Rani Anne, anne.bhargavi.rani.177@m.kyushu-u.ac.jp; $₫$ Shajahan Shaik, shajahaniiit@gmail.com; Masaki Tanaka, masaki@zaiko.kyushu-u.ac.jp; Anindya Basu, basua@nitrkl.ac.in | ${ }^{1}$ Department of Materials Science and Engineering, Faculty of Engineering, Kyushu University, Fukuoka 819-0395, Japan. ${ }^{2}$ Department of Metallurgical and Materials Engineering, National Institute of Technology, Rourkela 769008, India. ${ }^{3}$ Center for Elements Strategy Initiative for Structural Materials, Kyoto University, Kyoto 606-8501, Japan. ${ }^{4}$ Department of Chemistry and Green-Nano Materials Research Center, Kyungpook National University, Daegu 41566, Korea. 
decreases the brittleness of the material $[2,6]$. HEAs are credibly employed in high-temperature applications due to having high thermal stability, exceptional oxidation resistance, superior mechanical properties such as hightemperature strength, and thermal fatigue [7-10] that are achieved by compositional and structural features of HEAs. In recent days, much attention is given to HEAs in various research areas due to their credible applicability in many applications at extreme conditions [11-15] because of possessing remarkable properties. Additionally, easy implementation of HEAs' mass production is highly possible with existed equipment and technologies as HEAs do not require special processing techniques. Nearly more than $300 \mathrm{HEAs}$ were reportedly processed with more than 30 elements and their combinations to date [16].

Several significant works contributed to HEAs exhibiting excellent mechanical properties, oxidation, and corrosion resistances, etc. to date. Concerning high-temperature applications, oxidation resistance is the foremost property to consider. The oxidation resistance of conventional alloys can be improved by incorporating the elements those form a stable and thick oxide layer on the surface of a material at higher temperatures; for example, $\mathrm{Al}, \mathrm{Si}$, and $\mathrm{Cr}$ can significantly improve the oxidation resistance. In case of HEAs, investigation of oxidation resistance was performed only on selected HEAs that are CrMnFeCoNi [17], $\mathrm{CoCrFeNiAl}_{x}$ [18], CoCrCuFeNiSi ${ }_{x}$ [19] as they often exhibit good oxidation resistance majorly due to having $\mathrm{Al}, \mathrm{Cr}$, and Si elements. Furthermore, most of the research focused on HEAs' oxidation behavior as an effect of alloying addition. There were only limited significant works on the oxidation behavior of HEAs to date. Hence, the present review article summarizes those significant works on recent advances and developments in HEAs' oxidation study, emphasizing phase formation, and microstructural changes after the oxidation test. Current challenges and critical future directions in this field are also pointed out.

\section{Oxidation kinetics}

Oxidation kinetics are very crucial in understanding the oxidation behavior of any material that can be explained by the power law [20],

$\Delta m=k_{i} t^{n}$,

where mass gain per initial surface area after the oxidation is given by $\Delta m, k_{i}$ is the oxidation rate constant, and $\mathrm{t}$ is exposure time. The power-law exponent, $n$, defines the type of oxidation kinetics such as linear, parabolic, exponential, cubic growth rates. For example, oxidation kinetics follows linear growth when $n=1$, whereas they follow parabolic kinetics when $n=0.5$. The experimental oxidation kinetics will be determined by choosing the satisfactory values of $R^{2}$ (coefficient of determination) in mass gain per initial surface area $\left(\mathrm{mg} / \mathrm{cm}^{2}\right)$ vs. exposure time. The equation that governs mixed kinetics of parabolic and linear has been mentioned along with the corresponding study in the later section. The various oxidation kineticslaws reviewed in this article are presented as follows:

The linear kinetics are explained with the following equation [20]

$\Delta m=k_{l} t$,

The parabolic kinetics are explained with Eq. 3 [20]

$\Delta m^{2}=k_{p} t+c_{0}$

The equation used to explain cubic oxidation kinetics is given as follows [19]

$\Delta m^{3}=k_{c} t+c_{0}$

The exponential kinetics is given by the following equation [21]

$\Delta m=k_{e} \exp ^{(n t)}$,

where, $k_{l}, k_{p}, k_{c}, k_{e}$ are oxidation rate constants of linear, parabolic, cubic, and exponential kinetics, respectively. Few studies also calculated the experimental activation energy for oxidation given by the Arrhenius equation, as mentioned in Eq. 6 . The higher the activation energy, the greater the oxidation resistance, where higher activation energies are required for higher diffusion of cations/anions. The activation energy for oxidation also signifies the thermally activated oxidation mechanisms if they existed in the system. For example, few studies indicated that solid-state diffusion and breakaway oxidation occurs at lower and higher oxidation temperatures, respectively are thermally activated processes [20].

$k_{i}=k_{0} \exp \left(\frac{-E_{a}}{R T}\right)$,

where, $k_{i}$ and $E_{a}$ are oxidation rate constant and activation energy for oxidation, respectively. $k_{0}$ is the pre-exponential factor, $R$ is gas constant, and $\mathrm{T}$ is the oxidation test temperature. The formation enthalpies are also were calculated in a few studies that determine the formation of favorable oxide scales thermodynamically and which oxide scale is favorable to form first. The oxide compounds with the lowest formation enthalpy will be the first oxide scale to be formed on the alloy's surface. The formation enthalpy $\left(H_{f}\right)$ to form $\mathrm{X}_{\mathrm{n}} \mathrm{O}_{\mathrm{m}}$ oxide can be calculated by [22] 
$H_{f}=\left(E_{\text {tot }}-n E_{\text {solid }}^{X}-m \frac{E^{O_{2}}}{2}\right) /(n+m)$,

where, $n E_{\text {solid }}^{X}$ is the total energy per $X$ atom in a solid-state of crystal structure, $E^{\mathrm{O}_{2}}$ is the total energy of spin polarized $\mathrm{O}_{2}$ molecule, $E_{\text {tot }}$ is the total energy of the system.

\section{Recent updates of oxidation study in HEAs}

It is very crucial to choose suitable materials that ascertain mechanical and oxidation properties at higher temperatures to affirm the demand for high-temperature applications. Recently, several high entropy alloys (HEAs) have been developed and commenced using at higher temperatures that meet the demand and performance of high-temperature applications. Few HEAs typically have enhanced oxidation resistance due to sluggish diffusion and because of having specific elements such as $\mathrm{Al}, \mathrm{Cr}$, and Si $[2,23-26]$. Better oxidation resistance can be achieved by incorporating these elements such as $\mathrm{Al}, \mathrm{Cr}$, and $\mathrm{Si}$ by reducing oxygen diffusivity and solubility in the matrix and forming a denser protective oxide layer on the surface. This section briefly discusses the recent developments of oxidation study in both BCC and FCC based high entropy alloys. As mentioned earlier, Yeh et al. [2] and Cantor et al. [4] proposed the concept of HEAs in 2004, and several works have been carried out on HEAs latter. However, the oxidation behavior of HEAs is an essential topic, though a limited study is available till date. By considering the significance of the oxidation study in HEAs, a few research groups recently focused on this topic.

\subsection{BCC (Body-centered cubic)-HEAs}

Many of the HEAs investigated for the oxidation behavior among HEAs are BCC-HEAs, and most of the studied HEAs are Refractory HEAs (RHEAs). Most of the BCC-HEAs are incorporated with $\mathrm{Al}$ and $\mathrm{Si}$ addition as both act as a strong $\mathrm{BCC}$ stabilizer and forms the protective $\mathrm{Al}_{2} \mathrm{O}_{3}$ and $\mathrm{SiO}_{2}$ layers that favors the oxidation properties. $\mathrm{Cr}$ also benefits the oxidation properties along with $\mathrm{Al}$ and Si addition, which also stabilizes BCC [27]. The following case studies emphasize the oxidation behavior of BCCHEAs with a special attention dedicated to the effect of alloying addition. Senkov et al. [10] reported on the isothermal oxidation behavior of HEA $\left(\mathrm{Mo}_{0.5} \mathrm{Ta}_{0.5} \mathrm{TiZrNbCr}\right)$ at $1273 \mathrm{~K}$ for $100 \mathrm{~h}$ in the presence of air. This particular HEA consists of a major BCC1 phase and two minor phases that are BCC1 and FCC (laves). The assigned HEA was prepared using a vacuum arc melting process, and Thermax 700 TGA unit (Cahn Instruments, Madison, WI) was used to study the oxidation behavior of the alloy.
The entire experiment was carried out in a vertical furnace with a $15 \mathrm{~K} / \mathrm{min}$ heating rate and held for $100 \mathrm{~h}$ at $1273 \mathrm{~K}$, followed by furnace cooling with a cooling rate of approximately $10^{\circ} \mathrm{C} / \mathrm{min}$. Weight gain was automatically registered every $20 \mathrm{~s}$. Continuous weight gain of HEA was observed during the test by holding at $1273 \mathrm{~K}$. Before starting the experiment, the sample weight was measured as $1381.4 \mathrm{mg}$. However, after reaching the furnace's temperature to $1273 \mathrm{~K}$, the sample weight was increased to $1397.1 \mathrm{mg}$. Weight gain of the sample increased drastically with time for the first $10 \mathrm{~h}$ beyond which the weight gain increment became slow compared to the first $10 \mathrm{~h}$, as indicated in Fig. 4. Such type of behavior was described by power-law dependence, as shown in Eq. 1. Best fitting was observed with the time exponent, $\mathrm{n}=0.6$ and $\mathrm{k}_{1}=0.055 \mathrm{mg} \mathrm{cm}^{-2} \mathrm{~s}^{-0.6}$. After completing the oxidation test for $100 \mathrm{~h}$, the sample weight was measured as $1620.7 \mathrm{mg}$. During the cooling, the oxide layer was separated from the samples' surface due to different thermal expansion of the alloy and oxide. The average density of the oxide layer has been reported as $5.06 \pm 0.46 \mathrm{~g} \mathrm{~cm}^{-3}$.

Microstructure characterization after the oxidation test revealed the origin of crack formation in the region of FCC and $\mathrm{BCC} 2$ phases, which has been extended to the $\mathrm{BCC} 1$ phase. However, the $\mathrm{BCC} 1$ phase exhibited higher resistance to the cracking during oxidation when compared to the remaining phases. Moreover, the $\mathrm{BCC} 1$ phase is having larger volume expansion than the other two phases, leading distribution of tensile strains to other phases that caused cracking. Moreover, Gaussian distributions were also used to study the oxygen solubility of the existing phases using the equation, $C_{O}=A \cdot \exp \left[-(x / r)^{2} / 2\right]$, where $x$ represents the distance from the sample surface and $r$ is the standard deviation. Obtained results demonstrated that the diffusion rate of oxygen in the $\mathrm{BCC} 1$ phase was almost 25 times slower than in other phases (BCC2 and FCC phases). These results confirmed that the $B C C 1$ phase has higher oxidation resistance than the other two phases. Another point observed during the oxidation study is that limited diffusion of alloying elements in HEA leads to complex oxides formation. A slower diffusion rate could occur due to a lower concentration of free vacancies in HEAs. But it is quite different in the case of conventional alloys like $\mathrm{Nb}$-based developmental alloys in which metal oxide layer forms due to decreasing of alloying elements concentration inside the metal matrix and increasing in oxygen solubility ultimately suffer with internal oxidation [29, 30]. The isothermal oxidation results of corresponding HEA alloy in comparison with $\mathrm{Nb}$ based developmental alloys at $1273 \mathrm{~K}$ were summarized in Table 1. The comparison evidences the excellent oxidation resistance for $\mathrm{HEA}$ over $\mathrm{Nb}$ based alloys. However, two Nb-based alloys also exhibited 
Table 1 comparison of weight gain per unit surface area (in $\mathrm{mg} / \mathrm{cm}^{2}$ ) between $\mathrm{Mo}_{0.5} \mathrm{Ta}_{0.5} \mathrm{TiZrNbCr}[10]$ and $\mathrm{Nb}$-based alloys $[28,29]$ during isothermal holding at $1273 \mathrm{~K}$ in air

\begin{tabular}{lllllll}
\hline Alloy/time & $1 \mathrm{~h}$ & $2 \mathrm{~h}$ & $4 \mathrm{~h}$ & $24 \mathrm{~h}$ & $100 \mathrm{~h}$ & References \\
\hline $\mathrm{Mo}_{0.5} \mathrm{Ta}_{0.5} \mathrm{TiZrNbCr}$ (HEA) & 10 & 15 & 22 & 50 & 119 & {$[10]$} \\
$\mathrm{Nb}$ & 159 & 300 & - & - & - & {$[28]$} \\
$\mathrm{Nb}-10 \mathrm{Si}$ & 37 & - & - & - & - & {$[28]$} \\
$\mathrm{Nb}-10.1 \mathrm{Si}$ & 45 & 90 & 170 & - & - & {$[29]$} \\
$\mathrm{Nb}-17.3 \mathrm{Al}$ & 23 & 43 & 65 & - & - & {$[29]$} \\
$\mathrm{Nb}-5 \mathrm{Si}-9 \mathrm{Al}$ & 90 & 160 & 275 & - & - & {$[29]$} \\
$\mathrm{Nb}-7 \mathrm{Si}-9 \mathrm{Al}$ & 69 & 145 & 275 & - & - & {$[29]$} \\
$\mathrm{Nb}-8 \mathrm{Si}-9 \mathrm{Al}-10 \mathrm{Ti}$ & - & - & - & 182 & 338 & {$[29]$} \\
$\mathrm{Nb}-10 \mathrm{Si}-9 \mathrm{Al}-10 \mathrm{Ti}$ & - & - & - & 95 & 291 & {$[29]$} \\
$\mathrm{Nb}-6 \mathrm{Si}-11 \mathrm{Al}-15 \mathrm{Ti}$ & - & - & - & 51 & 167 & {$[29]$} \\
$\mathrm{Nb}-8 \mathrm{Si}-11 \mathrm{Al}-15 \mathrm{Ti}$ & - & - & - & 51 & 153 & {$[29]$} \\
$\mathrm{Nb}-12 \mathrm{Si}-15 \mathrm{Mo}$ & 1.3 & 1.4 & 4.0 & 15 & - & {$[28]$} \\
$\mathrm{Nb}-13 \mathrm{Si}-4 \mathrm{Mo}$ & 48 & 105 & 166 & - & - & {$[28]$} \\
$\mathrm{Nb}-18 \mathrm{Si}-26 \mathrm{Mo}$ & 9.7 & 13.8 & 19.5 & 45 & - & {$[28]$} \\
$\mathrm{Nb}-19 \mathrm{Si}-5 \mathrm{Mo}$ & 26 & 53 & 106 & - & - & {$[28]$} \\
\hline
\end{tabular}

excellent performance where the oxidation resistance of HEA is similar to that of Nb-18Si-26Mo and slightly lower than that of $\mathrm{Nb}-12 \mathrm{Si}-15 \mathrm{Mo}$ alloy [10].

The effect of core effects in achieving phenomenal oxidation behavior in HEAs was elucidated in BCC HEAs. The temperature dependence of oxidation behavior in TiZrNbTa has been investigated by Wang et al. [31] by considering the effect of severe lattice distortion. Their study emphasized that the severe lattice distortion strongly affects the diffusion rate of oxygen concerning oxidation temperatures. According to their results, TiZrNbTa exhibits two distinguishable oxidation phenomena caused by two different elemental diffusion trends: weaker lattice distortion and severe lattice distortion in TiNb-rich and TiZr-rich regions, the oxidation temperatures at which are between 1073 and $1673 \mathrm{~K}$, respectively. TiZr-rich regions where severe lattice distortion exists ascertain higher oxidation rates. The diffusion rate of oxygen atoms is explained by the dislocation pipe effect [32]. Figure 1 shows isothermal oxidation plots of TiZrNbTa; the oxidation rates are significantly different at $1273 \mathrm{~K}$ and above $1273 \mathrm{~K}$, resulting from the lattice distortion change. The oxidation rates increase with increasing temperature above $1273 \mathrm{~K}$, and it is vice-versa at $1073 \mathrm{~K}$, as shown in Fig. 1. The oxidation rates follow parabolic law (Eq. 3) above $1273 \mathrm{~K}$, caused by the homogenous and higher diffusion of oxygen atoms attributed to the TiZr-rich region. On the contrary, inhomogeneous diffusion of oxygen atoms, which leads to severe stress concentrations and disintegration of oxide scales into powders, has been evidenced at $1073 \mathrm{~K}$, resulting in a reverse trend of the oxidation rate (Fig. 1). Their study proposed that the correlation between diffusion rate of oxygen atoms and severe lattice distortion can be affirmed by the degree of lattice distortion, i.e., the slower diffusion rates are inevitable when the degree of lattice distortion

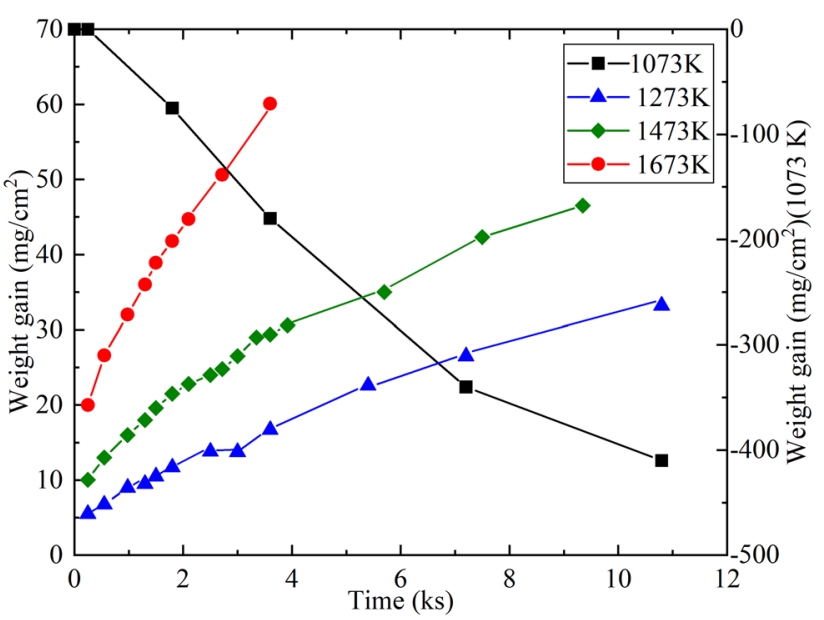

Fig. 1 Isothermal oxidation curves of TiZrNbTa HEA in the temperature range between 1073 and $1673 \mathrm{~K}$ [31]

to generate dislocation pipe is lower than the threshold value.

Liu et al. [33] studied the oxidation behavior of four different $\mathrm{HEAs}$ by varying alloying additions that are $\mathrm{Al}_{0.5} \mathrm{CrNbMoTi}(\mathrm{H}-\mathrm{Ti}), \mathrm{Al}_{0.5} \mathrm{CrNbMoV}(\mathrm{H}-\mathrm{V}), \mathrm{Al}_{0.5} \mathrm{CrNbMoTiV}$ $(\mathrm{H}-\mathrm{TiV})$, and $\mathrm{Al}_{0.5} \mathrm{CrNbMoTiVSi}_{0.3}\left(\mathrm{H}-\mathrm{TiVSi}_{0.3}\right)$ at $1573 \mathrm{~K}$ in air. In this study, $\mathrm{H}-\mathrm{Ti}, \mathrm{H}-\mathrm{V}$, and $\mathrm{H}$-TiV samples consist of single $\mathrm{BCC}$ phase whereas $\mathrm{H}-\mathrm{TiVSi}_{0.3}$ alloy composed with single $\mathrm{BCC}$ phase and $\left(\mathrm{Nb}, \mathrm{Ti}_{5} \mathrm{Si}_{3}\right.$ compound phase. Oxidation test was carried out for $20 \mathrm{~h}$ at $1573 \mathrm{~K}$, and weight gain was recorded every $5 \mathrm{~h}$ for each specimen. Overall, oxidation kinetics of all the samples asserted a linear relationship (Eq. 2) between weight gain and time. The primary focus of this work is to determine the effect of alloying elements on the oxidation behavior of HEAs, and the investigated 
results demonstrated that the addition of Si and Ti stimulates a drastic increase in oxidation resistance of the HEAs while it is vice-versa with $V$ addition as indicated in Fig. 2. A few observations were highlighted after incorporation of vanadium as follows: (i) initially, oxides of $\mathrm{H}$-Ti are compacted with very little porosity as shown in Fig. 3a, but the introduction of $V$ to the alloy led to harmful nature by exceptional increase in porosity, as shown in Fig. 3b, c, e, $f$. Increase in porosity encouraged more inward diffusion of oxygen at the interface between oxide and metal. (ii) Large sized pores were observed in the microstructure of $\mathrm{H}-\mathrm{V}$ (Fig. 3b) and H-TiV (Fig. 3c), where the oxide scales are $\mathrm{CrNbO}_{4}$ and $\mathrm{VO}_{x}$ in $\mathrm{H}-\mathrm{V}$ alloy (Fig. $3 \mathrm{~b}$ ) and $\mathrm{VO}_{x}$ has been observed in the vicinity of the pores in both the cases. These Pores became larger owing to fusion or volatilization of the $\mathrm{V}_{2} \mathrm{O}_{5}$ due to its low melting point. Thus, the oxidation rates will be increased in $\mathrm{H}-\mathrm{V}$ and $\mathrm{H}-\mathrm{TiV}$ alloys as there will be a higher chance for higher oxygen diffusion towards the metal-oxide interface. Therefore, $\mathrm{VO}_{\mathrm{x}}$ formation resulted in the evolution of large-sized pores in oxide layers of $\mathrm{H}-\mathrm{V}$ and $\mathrm{H}-\mathrm{TiV}$ alloys, which further led to the higher oxidation rates in both the alloys as shown in Fig. $3 e$, $\mathrm{f}$, respectively. Similarly, the effect of $\mathrm{Si}$ and $\mathrm{Ti}$ on the HEAs were discussed as follows: (i) in the case of $\mathrm{H}$-TiVSi $\mathrm{T}_{0.3}$, the oxide layer neither consists of $\mathrm{VO}_{\mathrm{x}}$ nor larger pores, as shown in Fig. $3 d$. This accounts the enhanced oxidation resistance after introducing Si element in HEAs, which inhibits the formation of harmful $\mathrm{VO}_{\mathrm{x}}$ (ii) $\mathrm{Nb}$ and $\mathrm{Ti}_{5} \mathrm{Si}_{3}$ compound phase can act as a physical diffusion-barrier for inward and outward diffusions of oxygen and metal ions, respectively in the $\mathrm{H}-\mathrm{TiVSi}_{0.3}$ alloy, leading to better oxidation resistance. (iii) $\mathrm{Al}_{2} \mathrm{O}_{3}$ oxide layer formation was noticed in all the HEAs. However, a more uniformed and compacted $\mathrm{Al}_{2} \mathrm{O}_{3}$ oxide layer formation was observed in case of $\mathrm{H}-\mathrm{TiVSi}_{0.3}$ that acts as a protective layer for further

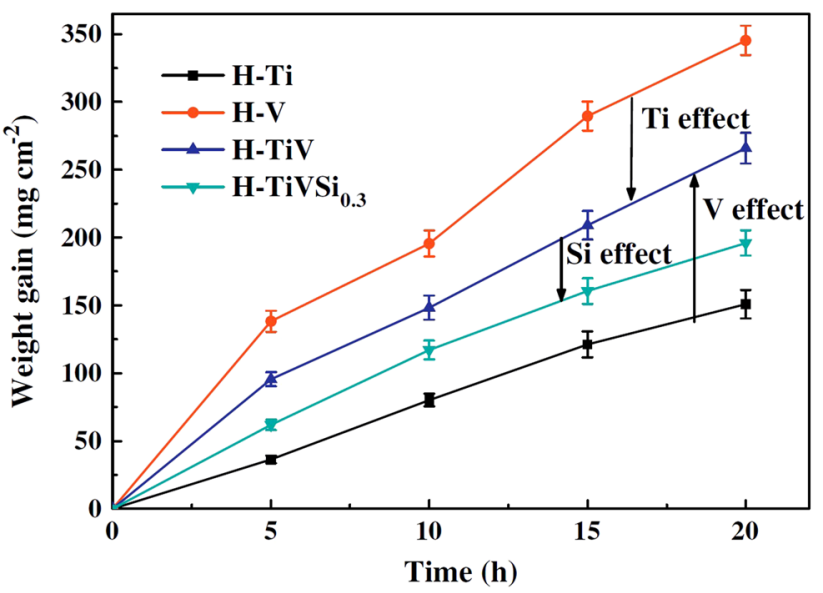

Fig. 2 The isothermal oxidation curves of $\mathrm{Al}_{0.5} \mathrm{CrNbMoTiVSi} \mathrm{HEAs}$ at $1573 \mathrm{~K}$, emphasizing the effects of $\mathrm{Ti}, \mathrm{Si}$, and $\mathrm{V}$ addition [33] inward oxygen diffusion. However, there was no significant effect observed with Ti addition on the alloy's oxidation property although the surface consisted of $\mathrm{CrNbO}_{4}$ $(\mathrm{TiCrNbV}) \mathrm{O}_{2}$. The significant effect of Ti on solid solubility and oxygen diffusivity in conventional alloys was reported earlier [34-36].

In another study, Gorr et al. [26] studied the effect of $\mathrm{Si}$ addition on the oxidation properties of HEAs $\left(\mathrm{NbMoAlCrTiSi}_{x}\right)$ at $1173 \mathrm{~K}, 1273 \mathrm{~K}$, and $1373 \mathrm{~K}$ for $48 \mathrm{~h}$. The HEAs are composed of a single BCC phase along with other minor phases like $\mathrm{Cr}_{2} \mathrm{Nb}$. Samples were prepared via arc-melting in $\sim 0.6$ atmosphere of Ar. Oxidation tests were performed on NbMoAlCrTi and $\mathrm{NbMoAICrTiSi}_{x}$ at the same temperatures and time intervals. However, NbMoAlCrTi alloy obeyed the liner oxidation kinetics (Eq. 2) at 1173 and $1273 \mathrm{~K}$. The oxidation rate is more at $1273 \mathrm{~K}$ due to the formation of non-protective oxide scales, while oxidation kinetics at $1373 \mathrm{~K}$ exhibited a lower oxidation rate compared to $1273 \mathrm{~K}$ after $48 \mathrm{~h}$ of exposure time. These results demonstrated that the formed oxide layer at $1373 \mathrm{~K}$ is partially protective after a longer oxidation time. However, $\mathrm{NbMoAICrTiSi}_{x}$ alloy obeyed the liner oxidation kinetics (Eq. 2) at $1173 \mathrm{~K}$, and parabolic law (Eq. 3) at $1273 \mathrm{~K}$ and $1373 \mathrm{~K}$ up to $30 \mathrm{~h}$ and beyond that changed to linear rate law. From their results, it was identified that the Si addition can show some advantages on the oxidation property of $\mathrm{NbMoAICrTi}$. According to earlier literature, there are two credible factors demonstrated with the Si addition as follows: (i) Si can form the protective silica layer at the interface between the substrate and oxide resulting in the reduced inward diffusion of oxygen. (ii) $\mathrm{SiO}_{2} \mathrm{can}$ act as nucleation sites for forming a homogenous protective oxide scale, which abates the inward and outward diffusions of oxygen and metal cations, respectively that aids in achieving better resistance towards oxidation. The mechanisms are same in this HEA as Si addition accounted for the enhanced oxidation resistance. $\mathrm{NbMoAICrTiSi}_{x}$ alloy evidenced lower mass gain at $1273 \mathrm{~K}$ and $1373 \mathrm{~K}$ over $\mathrm{NbMoAICrTi}$, which affirms the better oxidation resistance in HEA with Si. Nevertheless, the weight gain values, and oxidation resistance are similar in case at $1173 \mathrm{~K}$ for both the alloys, as shown in Fig. 4. Oxidation resistance has been enhanced with $\mathrm{Si}$ content that caused by forming continuous protective oxide layers of $\mathrm{Cr}_{2} \mathrm{O}_{3}$ and $\mathrm{Al}_{2} \mathrm{O}_{3}$ by increasing elemental activities of $\mathrm{Cr}$ and $\mathrm{Al}$ that rendered higher driving force to form such layers [37-39]. In contrast, HEA without $\mathrm{Si}$ addition evidenced the oxide layers that are porous, thick, and non-protective at $1173 \mathrm{~K}$. However, the formation of partially protective oxide layers of $\mathrm{Cr}$ rich and Al-rich were occurred at higher temperatures of $1273 \mathrm{~K}$ and $1373 \mathrm{~K}$, respectively. Gorr et al. [40] also studied the oxidation behavior of equimolar MoWAICrTi at $1273 \mathrm{~K}$ for $40 \mathrm{~h}$. This HEA alloy was prepared by arc-melting in $\sim 0.6$ 
Fig. 3 BSE images of oxide scales formed on the surfaces of HEAs at $1573 \mathrm{~K}$ for $10 \mathrm{~h}$. evidencing a $\mathrm{Al}_{0.5} \mathrm{CrNbMoTi}$ $(\mathrm{H}-\mathrm{Ti}), \mathbf{b} \mathrm{Al}_{0.5} \mathrm{CrNbMoV}(\mathrm{H}-\mathrm{V})$, c $\mathrm{Al}_{0.5} \mathrm{CrNbMOTiV}(\mathrm{H}-\mathrm{TiV})$, d $\mathrm{Al}_{0.5} \mathrm{CrNbMoTiVSi}_{0.3}$ $\left(\mathrm{H}-\mathrm{TiVSi}_{0.3}\right)$, and large sized pores in the oxide layers of HEAs e $\mathrm{Al}_{0.5} \mathrm{CrNbMoV}(\mathrm{H}-\mathrm{V}), \mathbf{f}$ $\mathrm{Al}_{0.5} \mathrm{CrNbMoTiV}$ (H-TiV) [33]
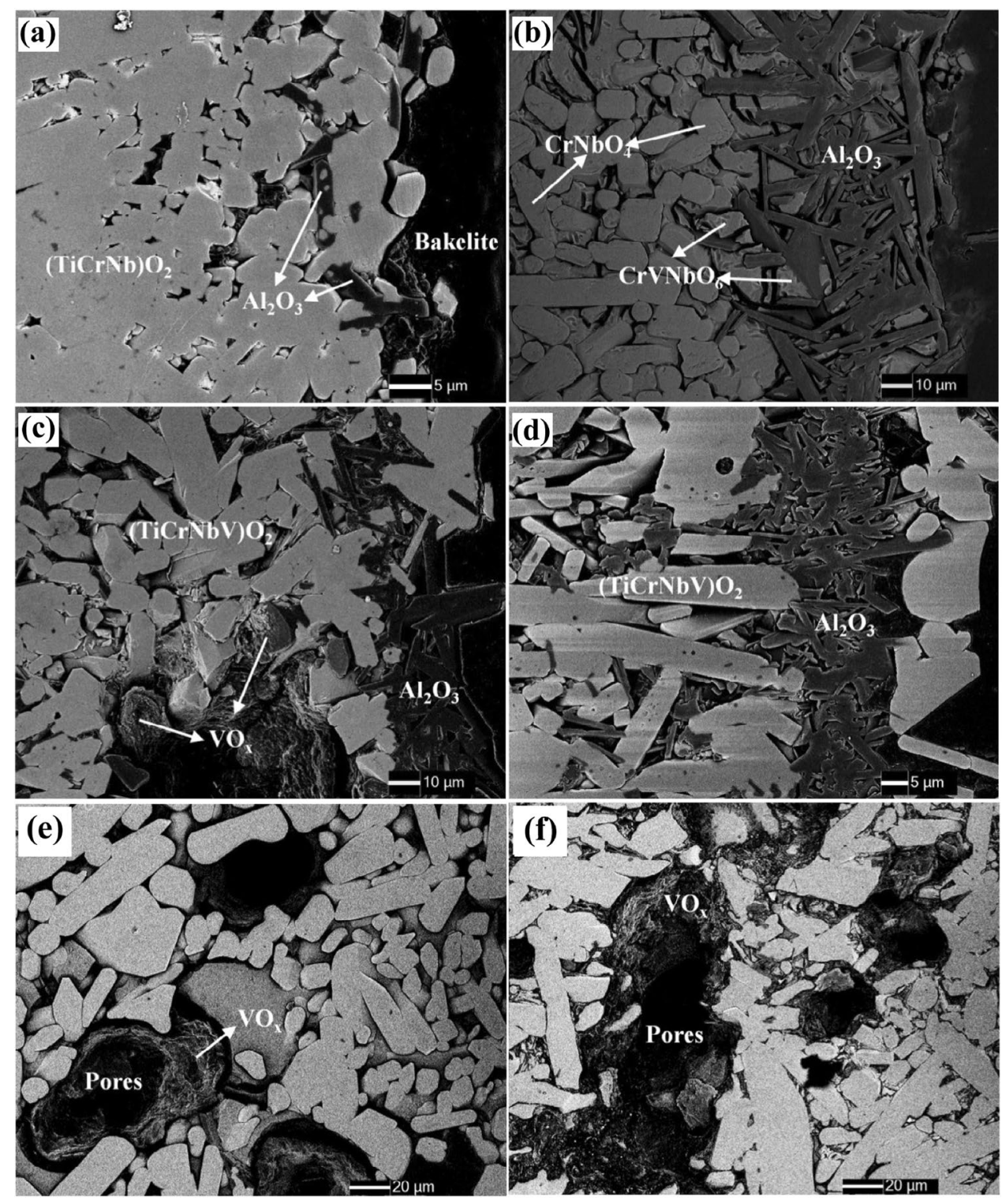

atmosphere of argon, as shown in Fig. 4. Oxidation kinetics of corresponding HEA followed the parabolic rate law (Eq. 3), demonstrating the growth of oxide layer by the solid-state diffusion. Positive values and the positive slope of the graph indicating the reduction in evaporation of volatile $\mathrm{W}$ and Mo oxides during the oxidation tests or completely hindered by the oxide scale formed on the substrate's surface. It proposes that the catastrophic oxidation by internal oxidation was not observed in the HEA. However, the oxidation rate is still significantly high in the alloy but the formation of homogenous protective oxide layers of $\mathrm{Al}_{2} \mathrm{O}_{3}$ or $\mathrm{Cr}_{2} \mathrm{O}_{3}$ are expected to form on the substrate by replacing the Ti with $\mathrm{Nb}$ in $\mathrm{HEA}$, where the oxidation resistance exceptionally enhanced by the addition of
$\mathrm{Nb}$ and avoiding $\mathrm{Ti}$ that promotes the formation of nonprotective and porous $\mathrm{TiO}_{2}$ layer. Unlike $\mathrm{HEAs}, \mathrm{Al}_{2} \mathrm{O}_{3}$ is not a protective layer in case of conventional alloys such as $\mathrm{TiAl}$, where the formed oxide scales were combination of $\mathrm{Ti}$ and $\mathrm{Al}$ that are mainly porous, thick, and non-protective [41].

The oxidation behavior investigation was continued on the RHEAs in the most recent studies as well. Zhang et al. [42] studied the oxidation behavior of NbZrTiCrAl at temperatures of $1073 \mathrm{~K}, 1273 \mathrm{~K}$, and $1473 \mathrm{~K}$ up to $50 \mathrm{~h}$ in air. HEAs were prepared by vacuum arc melting under pure Ar atm that has mostly BCC phase along with minimal fractions of $\mathrm{Al}_{2} \mathrm{Zr}$ and $\mathrm{Nb}_{2} \mathrm{Al}$ precipitates. $\mathrm{BCC}$ phase was occupied mainly by the microstructures of dendritic, 
Fig. 4 Isothermal oxidation plots of mass gain vs. exposure time in the major classes of BCC-HEAs; two plots indicated by red arrows belongs to Bottom $\mathrm{X}$, Left $\mathrm{Y}$-axes

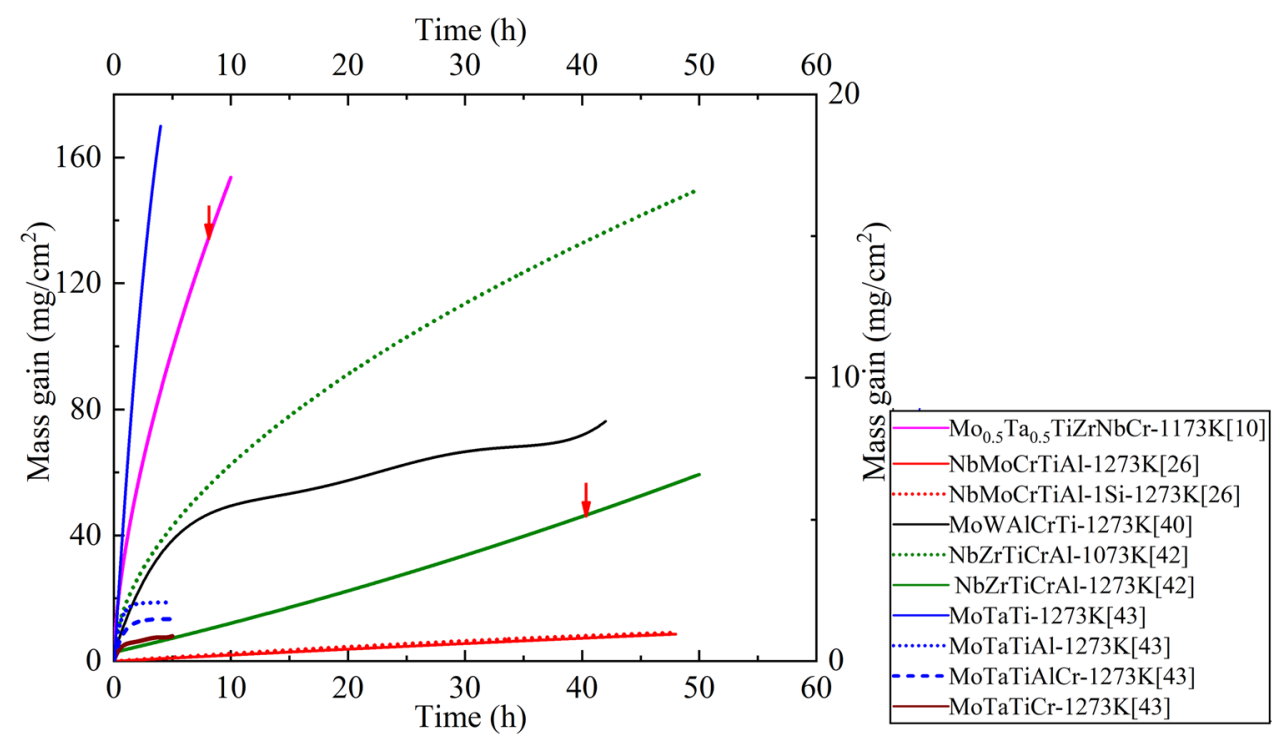

which has $\mathrm{Nb}$, Ti elements and inter-dendritic with $\mathrm{Al}$, $\mathrm{Cr}$, Zr. Oxidation kinetics followed parabolic rate law (Eq. 3) at 1073 and $1273 \mathrm{~K}$ and linear kinetics at $1473 \mathrm{~K}$. The oxidation resistance decreased as the temperature increases, and oxidation rate constants followed vice versa. The oxide scale was denser and continuous after $50 \mathrm{~h}$ at $1073 \mathrm{~K}$. In contrast, oxidation scales are adherent to the substrate up to $25 \mathrm{~h}$ and cracking and spallation occurred after $25 \mathrm{~h}$ at the higher temperatures of 1273 and $1473 \mathrm{~K}$. Mass gain was gradually increased throughout oxidation tests up to $50 \mathrm{~h}$. Mass gain initially followed slow growth up to $25 \mathrm{~h}$ and changed to fast reaction growth between 25 and $50 \mathrm{~h}$ at $1273 \mathrm{~K}$ as shown in Fig. 4. On the contrary, mass gain drastically increased from the starting at $1473 \mathrm{~K}$ due to cracking and spallation. However, similar oxide scales were formed in all three cases that are $\mathrm{TiO}_{2}, \mathrm{CrNbO}_{4}, \mathrm{ZrO}_{2}, \mathrm{Al}_{2} \mathrm{O}_{3}$, and $\mathrm{ZrNb}_{2} \mathrm{O}_{7}$. The oxidation mechanism of the NbZrTiCrAl-RHEA was compared with other RHEAs: the reported oxidation mechanism in $\mathrm{NbTiZrV}$ and $\mathrm{NbTiZrCr}$ is internal oxidation at higher temperatures. It was demonstrated that $\mathrm{Ti}, \mathrm{Nb}, \mathrm{Zr}$ elements have a higher affinity to oxygen at elevated temperatures in RHEAs that diminishes the protective layer's formation, such as $\mathrm{Al}_{2} \mathrm{O}_{3}$ and $\mathrm{Cr}_{2} \mathrm{O}_{3}$. The favorable oxide formation in NbZrTiCrAl-HEAs based on the Gibbs free energies of simple oxides' formation (Eq. 7) in ascending order as follows: $\mathrm{Cr}_{2} \mathrm{O}_{3}>\mathrm{Nb}_{2} \mathrm{O}_{5}>\mathrm{TiO}_{2}>\mathrm{Al}_{2} \mathrm{O}_{3}>\mathrm{ZrO}_{2}$. Aforementioned simple oxides at the initial stages of oxidation reacted with complex oxides such as $\mathrm{ZrNb}_{2} \mathrm{O}_{7}$ and $\mathrm{CrNbO}_{4}$ that correspond to the denser and continuous oxidation scales at all three temperatures. Still, the oxide scales have higher porosity at $1473 \mathrm{~K}$ though thicker and continuous layers formed.
Recent work on MoTaTiCrAl RHEAs proposed the enhanced oxidation resistance after removing $\mathrm{Al}$ addition. Li et al. [43] investigated the oxidation behavior of MoTaTiCrAl-based HEAs over a range of temperatures between 773 and $1273 \mathrm{~K}$ for $10 \mathrm{~h}$ exposure in the air. MoTaTi, MoTaTiAl, MoTaTiCr, and MoTaTiCrAl HEAs were prepared by arc melting under Ar atm. MoTaTi alloy initially showed better oxidation resistance at temperatures below $1273 \mathrm{~K}$, but the alloy underwent severe oxidation with the drastic increase in mass gain at $1273 \mathrm{~K}$, as shown in Fig. 4. All the other three alloys exhibited better oxidation resistance at $1273 \mathrm{~K}$ compared to that of MoTaTi alloy, as shown in Fig. 4. After $\mathrm{Cr}$ addition, i.e., in MoTaTiCr alloy, the mass gain initially increased slowly for the first one hour of the exposure, beyond which it reached a plateau throughout up to $10 \mathrm{~h}$ (Fig. 4). A similar trend of oxidation behavior as MoTaTiCr was also observed in Al added alloy, i.e., MoTaTiAl. However, the oxidation resistance of $\mathrm{Cr}$ added alloy was better than Al added HEA (Fig. 4). The oxidation resistance of the three alloys in descending order as follows: MoTaTiCr $>$ MoTaTiAl $>$ MoTaTiAICr $>$ MoTaTi as shown in Fig. 4. The oxidation resistance of the HEA after simultaneous addition of both the $\mathrm{Al}$ and $\mathrm{Cr}$ was better than MoTaTi and MoTaTiAl alloys but poor than MoTaTiCr alloy (Fig. 4). The poorest oxidation resistance in MoTaTi can also be affirmed by the oxide scales formed on the surface that are $\mathrm{TiO}_{2}$ and MoTiTa ${ }_{8} \mathrm{O}_{25}$, which are non-uniform, porous, and non-protective scales. The porosity was created by the evaporation of volatile Mo-based oxides as the temperature increases in the MoTaTi alloy. $\mathrm{Al}_{2} \mathrm{O}_{3}$ layer was formed along with the two above mentioned oxide scales in MoTaTiAl alloy due to which oxidation resistance was increased compared to MoTaTi alloy. However, the oxide layers in MoTaTiAl alloy also contained more porosity in the scales enriched with 
$\mathrm{Al}$ and the interface between oxidized and non-oxidized regions enriched with $\mathrm{Ti}$. The addition of Al failed to form the uniform and continuous layer that correlated to the poor oxidation resistance than MoTaTiCr. The addition of $\mathrm{Cr}$ in MoTaTiCr alloy formed the continuous, dense $\mathrm{CrTaO}_{4}$ layer that acted as a diffusion barrier for inward and outward diffusion of oxygen and metal cations, respectively, that accounted for the best oxidation resistance in MoT$\mathrm{aTiCr}$ among all the alloys. Despite forming the $\mathrm{CrTaO} 4$ layer in MoTaTiAICr alloy, the discontinuous formation of non-protective $\mathrm{TiO}_{2}$ and $\mathrm{Al}_{2} \mathrm{O}_{3}$ layers failed to prevent further oxygen diffusion. Thus, the study proposed that the MoTaTiCr-based HEAs exhibit better oxidation resistance for high-temperature applications by removing Al addition. A few more oxidation studies on similar BCC-HEAs are summarized in Table 2.

\subsection{Face-centered cubic HEAs (FCC-HEAs)}

In comparison with BCC-HEAs, there are fewer studies that investigated the oxidation behavior of FCC-HEAs. This review paper suggests that there is a great necessity to extend the investigation of oxidation behavior in FCCHEAs. In a few cases, as-cast BCC was transformed into FCC after heating the alloys to elevated temperatures for oxidation studies. In many studies, the FCC-HEAs were compared with the conventional FCC alloys. As similar to that of BCC-HEAs, the protective $\mathrm{Al}, \mathrm{Cr}$ based oxides along with Fe oxide are essential to yield better oxidation resistance and Ni, Co act as FCC stabilizers [27]. Liu et al. [18] reported the oxidation properties of $\mathrm{HEAs}$ by varying $\mathrm{Al}$ concentrations in AlCoCrFeNi HEA ( $\mathrm{Al}_{\mathrm{x}} \mathrm{CoCrFeNi}(\mathrm{x}=0.15$, $0.4)$ ) in supercritical water. They compared the HEAs outcome with HR3C steel. The HEAs with FCC solid solution used in this study were prepared using vacuum induction smelting and casting methods. The oxidation tests of all the specimens were performed at $823 \mathrm{~K}$ and $873 \mathrm{~K}$ for $70 \mathrm{~h}$ in supercritical water. Spinel type oxides were detected on the oxide layer formed on the samples' surface after the oxidation test, where $\mathrm{Al}_{0.15}$ and $\mathrm{HR} 3 \mathrm{C}$ contain a double spinel layer of $\mathrm{FeCr}_{2} \mathrm{O}_{4}$ and $\mathrm{Fe}_{3} \mathrm{O}_{4}$ as inner and outer layers, respectively. In contrast, $\mathrm{Al}_{0.4}$ only consisted of a single spinel layer, i.e., $\mathrm{FeCr}_{2} \mathrm{O}_{4}$. Moreover, the oxide layer formed on the surface of HEAs ( $\left.\mathrm{Al}_{x} \mathrm{CoCrFeNi}(\mathrm{x}=0.15,0.4)\right)$ was much thinner than the oxide layer formed on HR3C steel. The comparison affirms that HEAs acquire higher oxidation resistance over HR3C steel. The augmented oxidation resistance in $\mathrm{HEAs}$, especially, $\mathrm{Al}_{x} \mathrm{CoCrFeNi}$ is caused by the sluggish diffusion effect of HEAs and the formation of duplex oxide structure that consists of $\mathrm{Cr}$ rich inner layer and Fe rich outer layer. Though HR3C steel also consists of a duplex oxide layer, only the inner layer persists better oxidation resistance, and the outer layer is poorer to resist the oxidation, which is dissimilar from $\mathrm{HEA}$ with $\mathrm{Al}_{0.15}$ [18]. It has been widely reported fact that the presence of $\mathrm{Cr}$ and $\mathrm{Al}$ enhances the oxidation resistance of the HEAs as Al increases the lattice distortion in the alloy's lattice structure that results in preventing the atomic movement and elemental diffusion rate [54-57]. On the other hand, the existence of $\mathrm{Cr}$ contributes to the formation of $\mathrm{Cr}$-Fe mixed oxide film that further refrains the formation of a strong Fe oxide layer on the surface of HEAs, which results in a lower oxidation rate [18].

Chen et al. [58] also investigated the oxidation behavior of the same HEA, AlCrCoFeNi, with 0.6 wt $\%$ Al and $\mathrm{Si}$ addition. The study compared the oxidation behaviors of $\mathrm{Al}_{0.6} \mathrm{CrCoFeNi}$ and $\mathrm{Al}_{0.6} \mathrm{CrCoFeNiSi}_{0.3}$ (HEA-Si) at oxidation temperatures of $1073 \mathrm{~K}, 1173 \mathrm{~K}$, and $1273 \mathrm{~K}$ under ambient air in a furnace up to $100 \mathrm{~h}$. The initial as-cast specimens have an FCC + BCC crystal structure, but the specimens have only FCC structure after the oxidation tests. The dissolution of the BCC phase is accounted due to the metastable nature of $B C C$ in as-cast conditions. Also, the transformation of BCC to FCC after oxidation is credibly due to preferential oxidation of the BCC phase. The formation of $\mathrm{Al}_{2} \mathrm{O}_{3}$ and AIN (Aluminum Nitride) depletes the matrix in Al that destabilizes the BCC. BCC phase has been disappeared after the oxidation at all the temperatures in HEA without $\mathrm{Si}$ and beyond $1073 \mathrm{~K}$ in HEA-Si. However, HEA-Si after oxidation at $1073 \mathrm{~K}$ still contains a small amount of $\mathrm{BCC}$, which is due to the formation of Silicide precipitation on the surface of the alloys and weakening of $\mathrm{Al}_{2} \mathrm{O}_{3}$ scale, which demonstrates the effect of $\mathrm{Si}$ addition is stronger on the oxidation kinetics at $1073 \mathrm{~K}$ over HEA without $\mathrm{Si}$ compared to other temperatures. In all the conditions of both the alloys, an Al depleted zone was found due to the formation of AIN exempting HEA-Si at $1073 \mathrm{~K}$, and local spallation of oxide layers occurred at the depleted zones. $\mathrm{Al}_{2} \mathrm{O}_{3}, \mathrm{Cr}_{2} \mathrm{O}_{3}$, and ( $\left.\mathrm{Ni}, \mathrm{Co}, \mathrm{Fe}\right) \mathrm{Cr}_{2} \mathrm{O}_{4}$ spinel oxide scales were found in all the cases except additional $\mathrm{Cr}_{15} \mathrm{Co}_{9} \mathrm{Si}_{6}$ were detected in the case of HEA-Si at $1073 \mathrm{~K}$. Oxidation kinetics followed linear growth law (Eq. 2) at $1073 \mathrm{~K}$ in both the HEA without Si and HEA-Si alloys below $100 \mathrm{~h}$ oxidation times due to thin non-protective layers. It was expected that both the alloys would follow parabolic rate law (Eq. 3) beyond $100 \mathrm{~h}$ oxidation times by the formation of denser protective layers at $1073 \mathrm{~K}$. In contrast, both the alloys followed parabolic growth law at $1173 \mathrm{~K}$, as shown in Fig. 5 whereas they followed parabolic rate law and linear growth law in HEA without Si and HEA-Si, respectively at $1273 \mathrm{~K}$. Summarily, the study suggested that $\mathrm{Al}_{0.6} \mathrm{CrCoFeNiSi}_{0.3}$ alloy is suitable for applications up to $1073 \mathrm{~K}$ while $\mathrm{Al}_{0.6} \mathrm{CrCoFeNi}$ is not suitable for the hightemperature applications [58].

Recently, Shaik et al. [19] studied the effect of Si concentration on the oxidation behavior of HEAs 


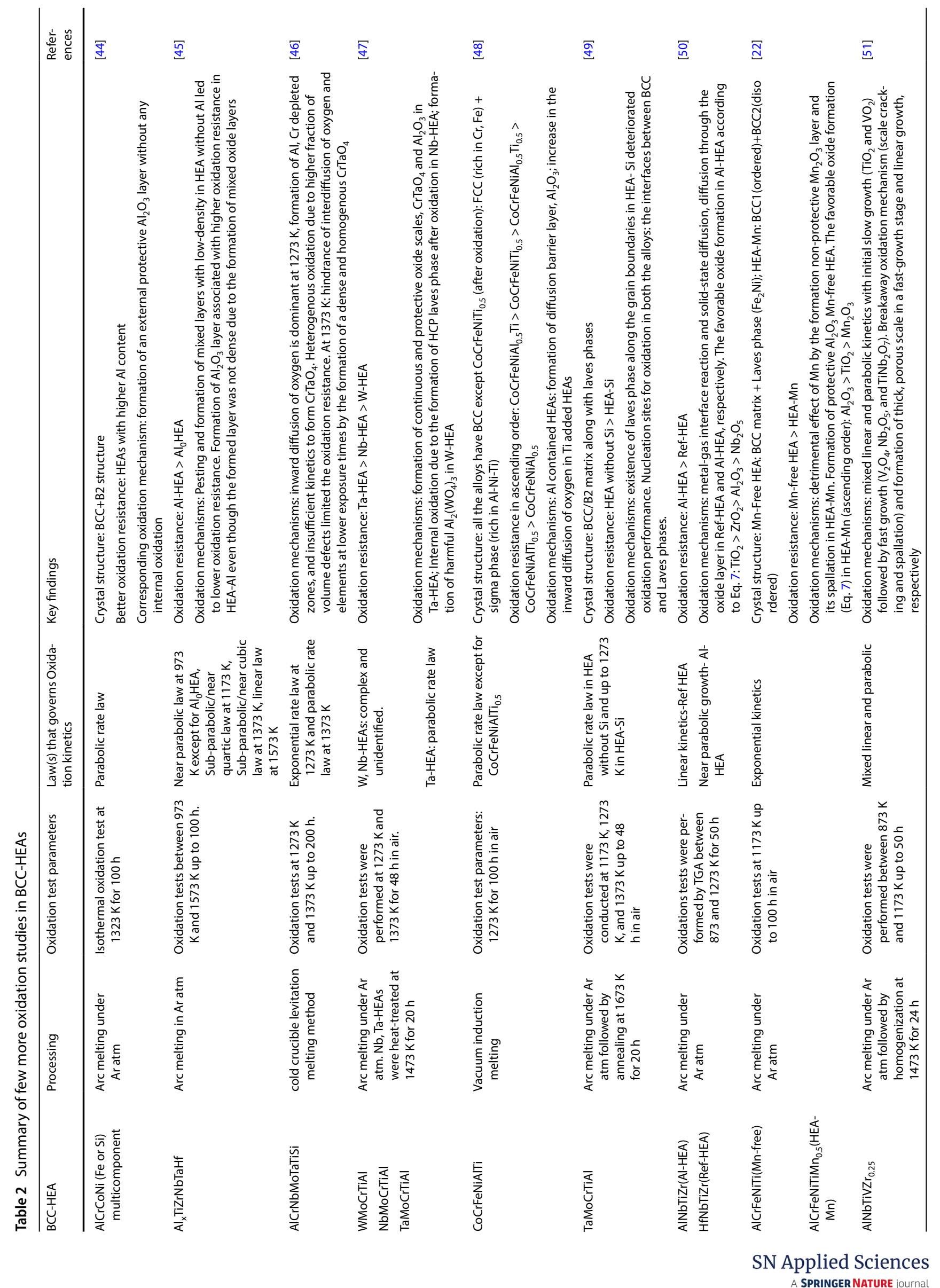




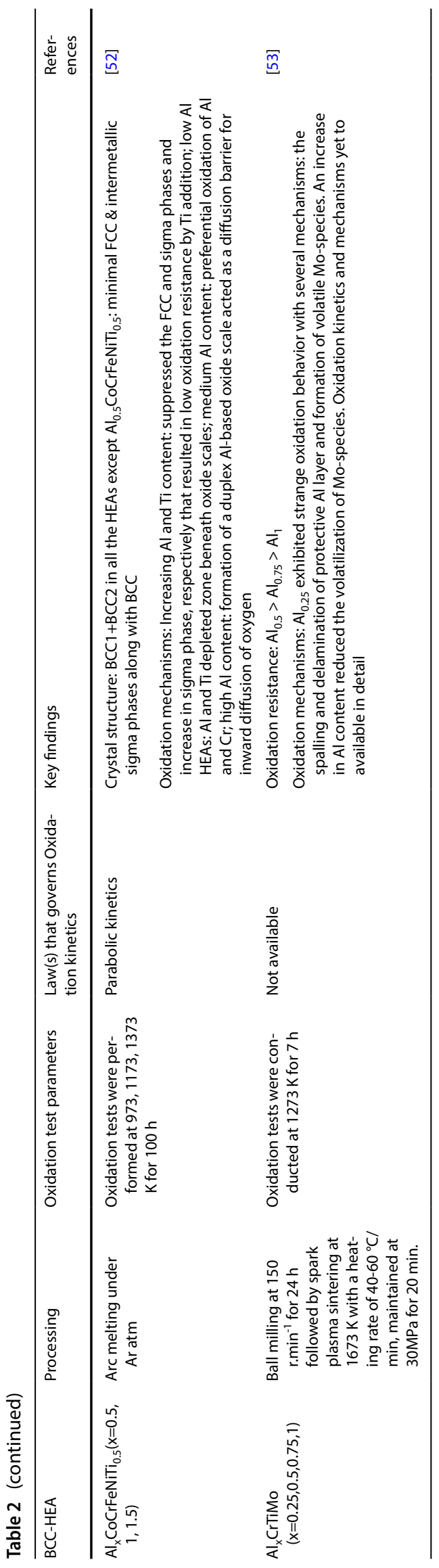

$\left(\mathrm{CoCrCuFeNiSi} \mathrm{x}_{(\mathrm{x}=0,0.3,0.6,0.9)}\right)$ and reported some important points on the oxidation behavior of HEAs, emphasizing the effect of Si. HEAs were processed by the powder metallurgy route i.e., high energy ball milling for $10 \mathrm{~min}$ followed by spark plasma sintering at $1273 \mathrm{~K}$ for $5 \mathrm{~min}$ by applying uniform load of $60 \mathrm{MPa}$. HEAs were oxidized at Room temperature, $873 \mathrm{~K}, 973 \mathrm{~K}$, and $1073 \mathrm{~K}$ for $30 \mathrm{~h}$. According to their study, Si content in HEA increased the oxidation resistance of HEA up to the addition of $0.6 \% \mathrm{Si}$ concentration beyond which oxidation resistance of the alloy decreased, as shown in the isothermal plot (mass gain vs. time) of HEAs at different temperatures (Fig. 5). The oxidation resistance of the investigated HEAs is as follows: $\mathrm{HEA}_{0.6 \mathrm{Si}}>\mathrm{HEA}_{0.3 \mathrm{Si}}>\mathrm{HEA}_{0.9 \mathrm{Si}}>\mathrm{HEA}$ (Si-free), as shown in Fig. 5. In their study, oxidation kinetics followed cubic law (Eq. 4). From Fig. 5, it was observed that the oxidation rate initially decreased with Si content at any tested temperature up to $0.6 \%$, latter it increased with $\mathrm{Si}$ content in the HEAs investigated. The following reasons can attribute such a change in the trend. 1) F1, F2, and $\sigma$ phases were detected after the spark plasma sintering process, among which the $\mathrm{F} 2$ phase is enriched with $\mathrm{Cu}$ content by which, $\mathrm{F} 2$ phase has been considered as highly prone to oxidization of $\mathrm{CuO}$ oxide. The amount of F2 phase fraction decreased with the addition of Si content due to which oxidation prone phase decreased that further reduced the oxidation rate in HEAs. 3) Concentration of sigma phase and lattice distortion increased with Si content, which helped in decreasing the oxidation rate in HEAs. However, the oxidation rate increased beyond $0.6 \%$ Si content, which was promoted by the increment in porosity with higher Si concentrations. Additionally, activation energies for oxidation were also calculated using Arrhenius equation (Eq. 6) in all the HEAs. The HEA without $\mathrm{Si}$ addition evidenced the lowest activation energy that indicates the higher diffusion of oxygen into the substrate, which also affirms the lowest oxidation resistance in HEA without $\mathrm{Si}$. Among HEAs with $\mathrm{Si}$ addition, $\mathrm{HEA}_{0.9 \mathrm{si}}$ has the lowest activation energy and thus, lowest oxidation resistance compared to $\mathrm{HEA}_{0.3 \mathrm{si}}$ and $\mathrm{HEA}_{0.6 \mathrm{Si}} \cdot \mathrm{HEA}_{0.6 \mathrm{Si}}$ demonstrated the highest activation energy for oxidation caused by the decrement in volume fraction of F2 phase.

In another study, the oxidation behavior of equimolar CoCrFeMnNi-HEA, a single solid solution of FCC, was investigated in the temperature range between 873 and $1173 \mathrm{~K}$ in laboratory air for $100 \mathrm{~h}$ [59]. The oxidation kinetics in this study are in good agreement with linear rate law at initial oxidation times followed by parabolic rate law as the oxidation time increases. Hence, the study used the general parabolic equation (Eq. 8) that constitutes both linear and parabolic terms to evaluate the oxidation kinetics. The 
Fig. 5 Isothermal oxidation plots of mass gain vs. exposure time in the major classes of FCC-HEAs; plots indicated by red arrows belongs to Top $X$, Right Y-axes

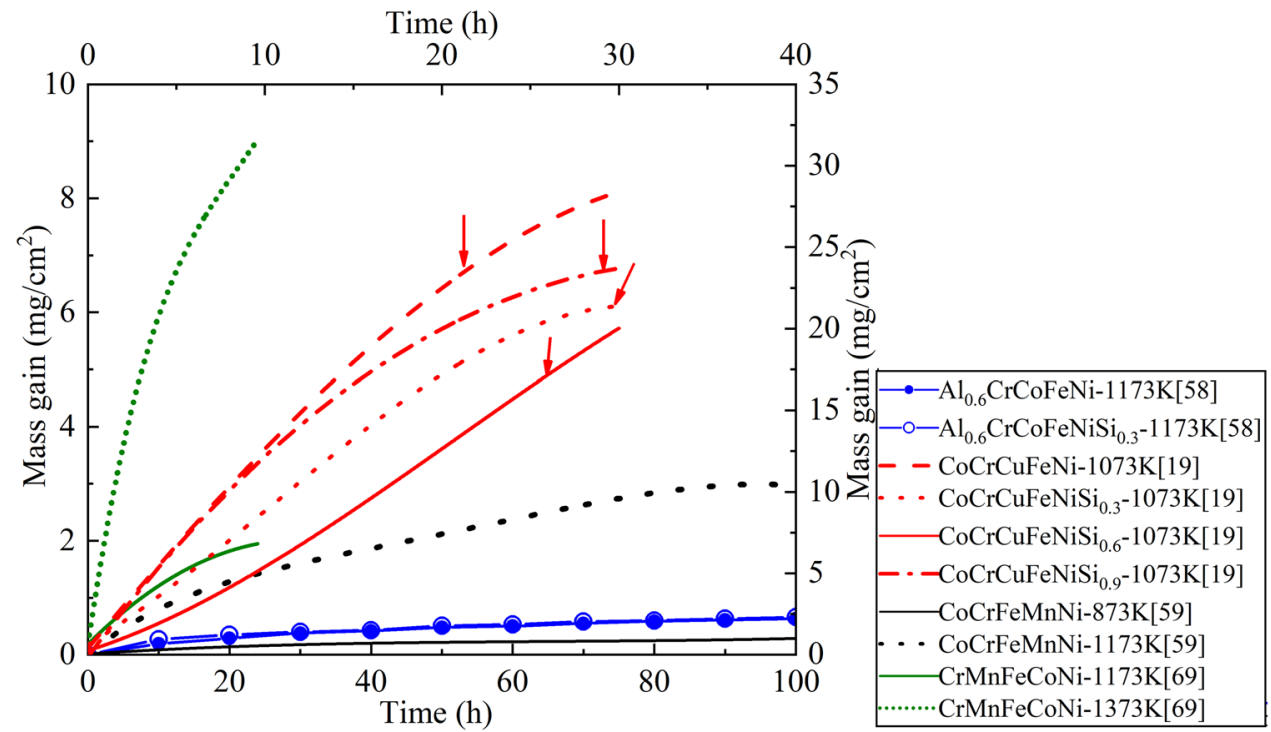

Eq. 8 comprises of the parabolic rate constant, and the linear rate constant is defined by the ratio of $k_{p} / k_{2}$.

$\left(\frac{\Delta W}{A}\right)^{2}+k_{2} \frac{\Delta W}{A}=k_{p} t$

Among both the linear and parabolic regions, the linear region at lower oxidation times denotes a non-protective oxide layer, whereas, at higher oxidation times, the oxide layer becomes protective, which is presented by the parabolic term in Eq. 8 that constitutes of thermal diffusion as a rate-limiting process. Oxidation resistance decreased as the temperature increased, as shown in Fig. 5. This study emphasized the effect of temperature on the formation of different types of $\mathrm{Cr}$ and $\mathrm{Mn}$-based oxides on the surface of HEAs. The formation oxide scales at different temperatures is as follows: $\mathrm{a}-\mathrm{Mn}_{2} \mathrm{O}_{3}$ along with a thin $\mathrm{Cr}_{2} \mathrm{O}_{3}$ scale at $873 \mathrm{~K}$, while it is $\mathrm{Mn}_{3} \mathrm{O}_{4}$ at $1173 \mathrm{~K}$. Thin $\mathrm{Cr}_{2} \mathrm{O}_{3}$ was diminished as the oxidation temperatures increases, which is different from $873 \mathrm{~K}$. At higher temperatures, the HEA substrate is depleted in Mn due to the formation of denser oxide scales by transforming a-Mn $\mathrm{Mn}_{3}$ to $\mathrm{Mn}_{3} \mathrm{O}_{4}$. Their study suggested that the formation of pores near oxide interfaces due to the depletion of $\mathrm{Mn}, \mathrm{Cr}$ causes a significant difference to the diffusion paths that further alter the oxidation resistance of the HEAs [59]. The study also compared the isothermal oxidation behavior of HEA with Mn-rich conventional alloys to emphasize the effect of $\mathrm{Mn}$. The outer thick Mn layer formed by the faster diffusion of Mn in FeMnAl alloys [60-63], which is two folds faster than $\mathrm{Cr}$ diffusion in Fe-Cr based alloys [64-68]. The faster diffusion of $\mathrm{Mn}$ over $\mathrm{Cr}$ in $\mathrm{Mn}$-rich alloys is similar to that of HEA. Also, various studies have been reported that higher Mn concentrations exhibit detrimental oxidation behavior over a wide range of $\mathrm{Cr}$ concentrations as a result of the oxide scale spallation $[60,65,66]$. The depletion of Mn by forming a thick Mn oxide layer in austenitic SS steel destabilizes the FCC austenite that further consequences in forming the BCC ferrite layer below the oxide scales [67, 68]. On the contrary, selective removal of $\mathrm{Mn}$ in $\mathrm{CoCrF}-$ eMnNi-HEA cannot destabilize the FCC structure as occurs in other conventional FCC alloys due to equimolar compositional elements in CoCrFeMnNi-HEA, which are all FCC at room temperature.

A similar study has been investigated on the CrMnFeCoNi-HEA to determine oxidation behavior at $1173 \mathrm{~K}$, $1273 \mathrm{~K}$, and $1373 \mathrm{~K}$ for $24 \mathrm{~h}$ under $79 \% \mathrm{~N}_{2}$ and $29 \% \mathrm{O}_{2}$ atm [17]. Valence Electron Concentration (VEC) values ascertain the crystal structure of the HEA to be FCC or BCC. Only the BCC phase will have existed when the VEC is less than 6.87, the VEC to yield FCC structure is $\geq 8.0$, whereas it is $\geq 6.87$ and $<8.0$ would result in $\mathrm{FCC}+\mathrm{BCC}$ structure. The calculated VEC, atomic size difference $(\delta)$, and $\Omega$ are $\approx 8,<4 \%$, and $\approx 7.4$, respectively in CrMnFeCoNi alloy. $\Omega$ is defined as $\Omega=T_{m} . \Delta S_{\text {mix }} / H_{\text {mix }}$, where $T_{m}, \Delta S_{\text {mix }}, H_{\text {mix }}$ are melting point, mixing entropy, and mixing enthalpies of the alloy, respectively. Thus, $\mathrm{CrMnFeCoNi}$ in this study has a random FCC solid solution. The oxidation behavior results determined that oxidation kinetics followed parabolic growth law (Eq. 3) at all three temperatures where the parabolic rate constant, $k_{p}$ increased with increasing oxidation temperature. The oxidation resistance of the HEA decreased as temperature increases that resulted by the rise in weight gain with an increase in oxidation temperature as shown in Fig. 5. The oxidation behavior of HEA was compared with SUS 405 SS steel [69]. CrMnFeCoNi HEA exhibited superior oxidation resistance over SUS 405 SS steel at $1273 \mathrm{~K}$. Nevertheless, SUS 405 SS steel outperformed HEA's oxidation 
behavior at lower oxidation temperatures that proposes that $\mathrm{CrMnFeCoNi}$ alloy is suitable for high-temperature applications over SUS 405 SS steel. HEA experiences spallation, kirkendall pores, atom concentration changes, and transformation of $\mathrm{Mn}_{2} \mathrm{O}_{3}$ to $\mathrm{Mn}_{3} \mathrm{O}_{4}$ abates the better oxidation resistance at higher temperatures. The microstructural characterization revealed that the oxide scales at $1173 \mathrm{~K}$ are $\mathrm{Mn}_{2} \mathrm{O}_{3}$ and $\mathrm{Cr}_{2} \mathrm{O}_{3}$, whereas they are $\mathrm{Cr}_{2} \mathrm{O}_{3}$ and $(\mathrm{Mn}$, $\mathrm{Cr})_{3} \mathrm{O}_{4}$. Preferential oxidation took place at some places, as shown in Fig. 6 a at $1173 \mathrm{~K}$, due to internal diffusion of metal cations or faster oxygen diffusion via grain boundaries. The oxide scale of spinel was noticed at $1173 \mathrm{~K}$, as shown in Fig. 6b. Much more fast oxide growth was clearly observed at $1273 \mathrm{~K}$ along the grain boundaries, as shown in Fig. $6 \mathrm{c}$. Cracks in oxide layer and spallation were identified at $1273 \mathrm{~K}$, as shown in Fig. $6 \mathrm{~d}$ instead of spinel oxide layers those observed at $1173 \mathrm{~K}$. At $1373 \mathrm{~K}$, the formed oxidation layers were thicker and denser by which the grain boundaries are not distinguishable as shown in Fig. 6e, and non-uniform, thicker, and non-spinel-based layer was detected at $1373 \mathrm{~K}$ as shown in Fig. 6f. In CrMnFeCoNi HEA, the oxidation behavior was strongly influenced by the existence of $\mathrm{Mn}$ and $\mathrm{Cr}$ oxides, also by the spallation of $\mathrm{Mn}$ and $\mathrm{Cr}$ oxides at higher temperatures. The study emphasized that grain boundaries are the weakest and nucleation sites to promote the oxidation, further lowering the oxidation resistance at higher temperatures [17].

Recent studies on the oxidation behavior of FCC-HEAs focused on heavy concentrated HEAs in which one of the multi-component elements will be in high concentration. Kai et al. [70] investigated the oxidation behavior of $\mathrm{Ni}_{2} \mathrm{FeCoCrAl}_{\mathrm{x}}(\mathrm{x}=0,0.5,1)$ in the temperature range between 873 and $1173 \mathrm{~K}$ up to $48 \mathrm{~h}$ in dry air. The HEAs with Al-free and low Al concentrations have a single FCC structure, while the HEA with the highest Al content has $\mathrm{FCC}+\mathrm{BCC}$ phase because Al acts as a strong BCC stabilizer. The microstructural characterization affirmed that the FCC phase is enriched in $\mathrm{Fe}, \mathrm{Co}, \mathrm{Cr}$ while the BCC phase is enriched in $\mathrm{Ni}$ and $\mathrm{Al}$. Oxidation resistance increased as the oxidation temperature lowers from 1173 to $873 \mathrm{~K}$, while $\mathrm{Al}$-free $\mathrm{Ni}_{2} \mathrm{FeCoCr} \mathrm{HEA}$ evidenced poor oxidation resistance among the three HEAs investigated. The oxidation resistance of the HEAs in ascending order as follows: $\mathrm{Ni}_{2} \mathrm{FeCoCr}<\mathrm{Ni}_{2} \mathrm{FeCoCrAl}{ }_{0.5}<\mathrm{Ni}_{2} \mathrm{FeCoCrAl}$ (Fig. 7a) that is the alloy with $\mathrm{FCC}+\mathrm{BCC}$ phase ascribed better oxidation resistance that was explained by the oxidation kinetics and the scales formed on the surfaces of the HEAs. Increasing $\mathrm{Al}$ concentration increased the lattice distortion in the matrix and formed the protective $\mathrm{Al}_{2} \mathrm{O}_{3}$ layer that consequences in better oxidation resistance. Oxidation kinetics at $873 \mathrm{~K}$ is too slow to be determined up to $48 \mathrm{~h}$ as the nucleation and growth of oxides were much longer than the exposure. The oxidation kinetics followed parabolic growth law at temperatures greater than or equal to $973 \mathrm{~K}$ in the three alloys. However, the parabolic growth law persisted throughout at $973 \mathrm{~K}$, whereas it followed multiplestage growth at higher temperatures ( $1073 \mathrm{~K}$ and $1173 \mathrm{~K}$ ). Two-stage and three-stage kinetics were observed in Alfree HEA and HEA with Al, respectively, where the solidstate diffusion is the rate-determining step in both the cases. Two-stage kinetics comprised of slow initial growth stage and fast-reaction stage, while three-stage kinetics has an extended stage of steady-state growth region [70].

Oxidation rate constants were calculated in the temperature range between 973 and $1173 \mathrm{~K}$; the effect of $\mathrm{Al}$ on the oxidation rate constants also was investigated. In Al-free $\mathrm{Ni}_{2} \mathrm{FeCoCr} \mathrm{HEA}$, the oxidation rate constants in the initial slow growth rate remained nearly constant while decreasing in the fast-reaction stage as temperature increases. In the two alloys with Al content, oxidation rate constants were reduced with increasing temperature in the initial slow growth stage. In contrast, the oxidation rate constants increased with increasing temperature in the steady-state growth stage. Nevertheless, oxidation rate constants decreased with increasing the temperature, as shown in Fig. 7b, which suggests better oxidation resistance with increasing $\mathrm{Al}$ content. The oxidation scales in all the conditions exempting $873 \mathrm{~K}$ are revealed to be in good cohesion with the substrate along with numerous pores in the scales. The oxide scales in Al-free HEA and HEA with Al are $\mathrm{Cr}_{2} \mathrm{O} 3$ and $\mathrm{Al}_{2} \mathrm{O}_{3}$, respectively at $873 \mathrm{~K}$. A non-uniform and granular $\mathrm{Al}_{2} \mathrm{O}_{3}$ was observed at $973 \mathrm{~K}$ for $\mathrm{HEAs}$ with $\mathrm{Al}$ content while it is the combination of $\mathrm{FeCr}_{2} \mathrm{O}_{4}$ and $\mathrm{NiCO}_{2} \mathrm{O}_{4}$ as an outer layer and $\mathrm{Cr}_{2} \mathrm{O}_{3}$ as an inner layer at 1073 and $1173 \mathrm{~K}$. The outward diffusion of metal cations and inward diffusion of oxygen atoms attribute to the oxidation behavior of the alloys, where the diffusion of cations/anions increased with increasing the oxidation temperature that deteriorated the oxidation behavior at higher temperatures. The study also discussed the diffusivity of $\mathrm{Al}$ in two HEAs with Al. The FCC + BCC dual-phase matrix was also prevailed despite the formation of $\mathrm{Al}$ scale in $\mathrm{Ni}_{2} \mathrm{FeCoCrAl}$ HEA by the simultaneous oxidation of the BCC phase (AIrich) FCC phase depleted with Al content. Although the two HEAs with Al content have a low concentration of Al, the continuous and uniform Al oxide scale was formed on the surface of both the HEAs that indicates that the diffusivity of $\mathrm{Al}$ is much higher than other elements in $\mathrm{Ni}_{2} \mathrm{FeCoCrAl} \mathrm{HEA} \mathrm{[70].} \mathrm{The} \mathrm{results} \mathrm{of} \mathrm{Holcomb} \mathrm{et} \mathrm{al.} \mathrm{[71]}$ also featured the importance of $\mathrm{Cr}$ addition to improving the oxidation resistance of $\mathrm{CoCrFeMnNi} \mathrm{HEAs.} \mathrm{A} \mathrm{total} \mathrm{of} 8$ $\mathrm{CoCrFeMnNi-based} \mathrm{HEAs} \mathrm{by} \mathrm{varying} \mathrm{Cr}$, Mn compositions were investigated for oxidation behavior at $923 \mathrm{~K}$ and $1023 \mathrm{~K}$ up to $1100 \mathrm{~h}$ in laboratory air. The oxidation behavior of HEAs has been compared with $304 \mathrm{H}$ stainless steel and $230 \mathrm{Ni}$ superalloy. Higher diffusion coefficients and 
Fig. 6 Oxidation scales after oxidation tests at different temperatures for $24 \mathrm{~h}$ in $\mathrm{CrM}$ nFeCoNi HEA. a, b $1173 \mathrm{~K}$, c, d $1273 \mathrm{~K}, \mathbf{e}, \mathbf{f} 1373 \mathrm{~K}$ [17]
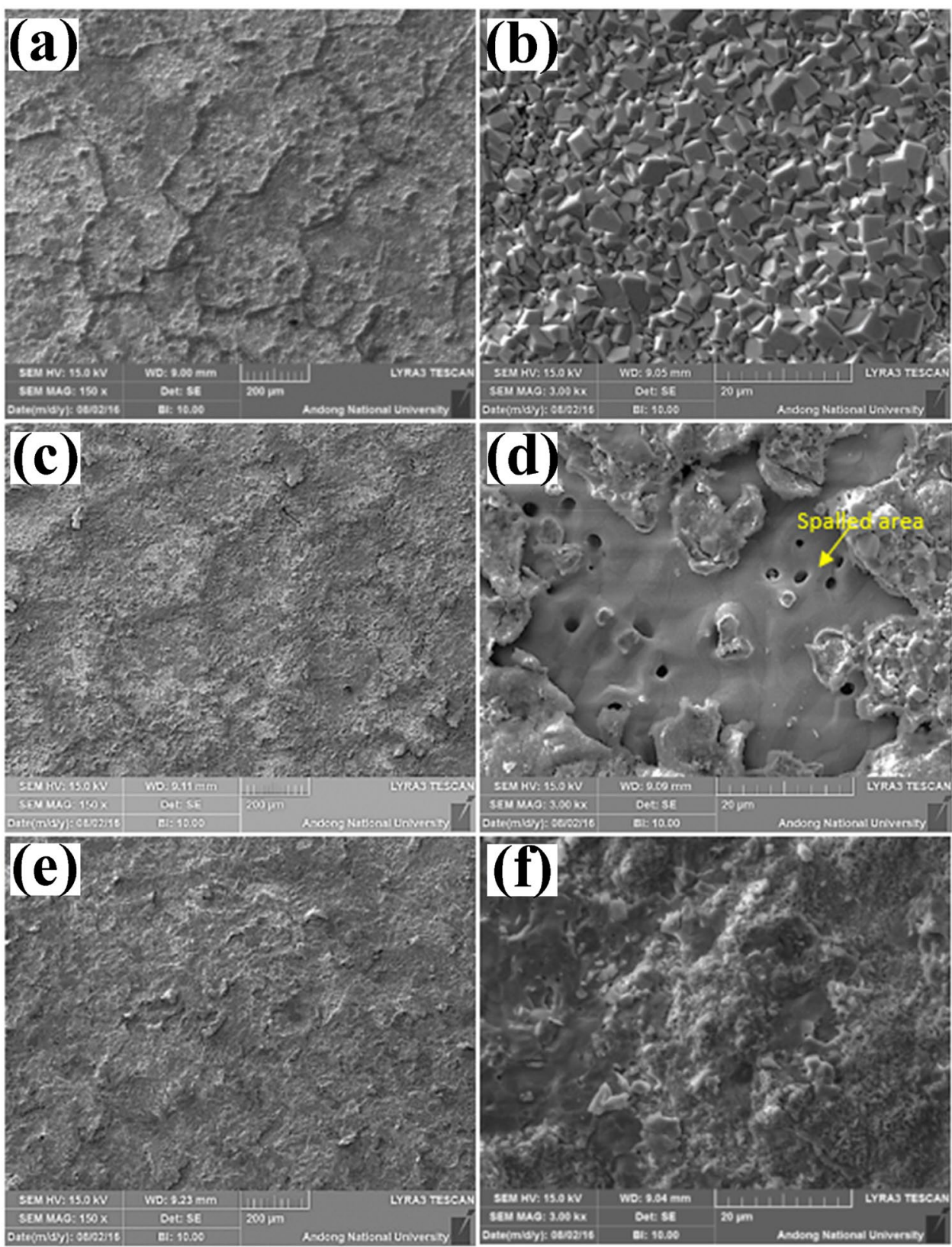

lower activation energies in conventional FCC alloys are reported than in CoCrFeMnNi, which is FCC solid solution. In this study, only one HEA (HEA-1) with higher $\mathrm{Cr}$ content and slight additions of $\mathrm{Al}, \mathrm{Mn}$ exhibited higher activation energies than conventional $304 \mathrm{H} \mathrm{SS}$ steel and $230 \mathrm{Ni}$ superalloy at $923 \mathrm{~K}$. However, higher activation energies were reported in $304 \mathrm{H} \mathrm{SS}$ steel and $230 \mathrm{Ni}$ superalloy over HEA-1 at $1023 \mathrm{~K}$. Their study emphasized the effect of $\mathrm{Cr}$ on the oxidation behavior of HEAs and conventional FCC alloys. The $\mathrm{Cr}$ concentration in $230 \mathrm{Ni}$ superalloy is similar to that of HEA-1, which is the primary reason for better or similar oxidation behavior exhibited by $230 \mathrm{Ni}$ superalloy to that of HEA-1. In the other investigated $7 \mathrm{HEAs}$, the $\mathrm{Cr}$ concentration is lower than that of $230 \mathrm{Ni}$ superalloy and HEA-1 along with higher Mn concentrations. HEAs were reported to perform poor oxidation behavior over 304H SS steel despite having high $\mathrm{Cr}$, Ni contents, and sluggish diffusion effect. Their study acknowledged the reduction in diffusion rate by the early formation of a thin $\mathrm{Cr}$ oxide layer due to the addition of $\mathrm{Cr}$ in HEAs. They also suggested that the outer layer of $\mathrm{Mn}$-based oxide also improves the oxidation properties of HEAs exclusively in the alloys with lower 

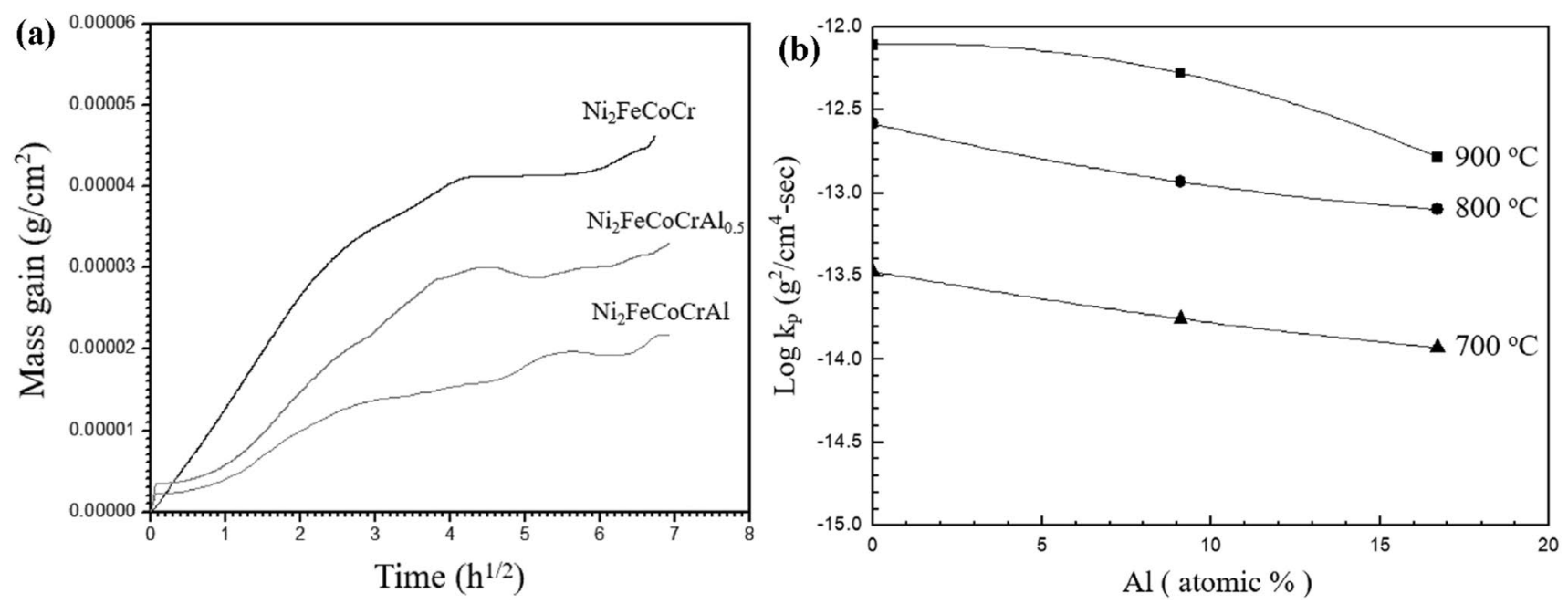

Fig. 7 The effect of Al content on the oxidation behavior of $\mathrm{Ni}_{2} \mathrm{FeCoCrAl}_{\mathrm{x}}$ alloy. a Parabolic plots of oxidation kinetics at $873 \mathrm{~K}$, $\mathbf{b}$ Parabolic rate constants in the steady-state region at different temperatures [70]

Mn concentration. Higher Mn concentrations have a detrimental effect on the oxidation behavior of both FCC-based HEAs and conventional FCC alloys due to the formation of a thicker Mn-Spinel oxide scale that significantly enhances outward diffusion of metal cations [72]. Few other significant oxidation studies on similar HEAs are presented in Table 3.

\section{Few extended miscellaneous works}

On the other hand, few studies on HEAs were also focused on HEAs as binders and coating materials to improve the oxidation resistance of materials. Zhu et al. [81, 82] synthesized dense $\mathrm{Ti}(\mathrm{C}, \mathrm{N})$ cermets by using $\mathrm{Ni} / \mathrm{Co}$ bimetallic (conventional) and HEA (AICoCrFeNi) binders. Their results observed that the cermet synthesized with a HEA binder exhibits appreciable oxidation resistance over the conventional $\mathrm{Ni} / \mathrm{Co}$ binder. The poor oxidation resistance associated with cermet using a conventional binder is due to inward oxygen diffusion through micro-cracks and pores formed in the oxide scales, as shown in Fig. 8a. The existence of micro-cracks, voids, and pores is much apparent in the enlarged view of the intermediate reaction layer, as shown in Fig. $8 \mathrm{c}$. The cermet with conventional binder contains less protective oxide layers such as inner $\mathrm{TiO}_{2}$, $\mathrm{Ti}_{3} \mathrm{O}_{5}, \mathrm{NiMoO}_{4}$, Outer $\mathrm{CoNiO}_{2}$, and $\mathrm{NiTiO}_{3}$ intermediate layers. Ti-based oxides and a mixture of $(\mathrm{Co}, \mathrm{Ni})$ oxides are visible as grey white and bright white scales in Fig. 8c. On the other hand, Cermet with HEA binder consisted of dense, stable, compact, and adherent oxide scales that are an external layer of $\mathrm{FeO}, \mathrm{CoO}, \mathrm{WO}_{3}$, an intermediate layer of $\mathrm{NiWO}_{4}, \mathrm{Cr}_{2} \mathrm{WO}_{6}$, and an inner layer of $\mathrm{TiO}_{2}$ along with small amounts of $\mathrm{TiMoO}_{5}$, and $\mathrm{AlTiO}_{2}$. The formation of dense microstructure was evidenced in cermet with HEA binder, as shown in Figs. 8b, d, which apparently continues higher oxidation resistance.

HEAs were also used in coating technology more than a decade ago. Huang et al. [54] synthesized two of the HEAs coating: $\mathrm{AlCrFeMo}_{0.5} \mathrm{NiSiTi}$ and $\mathrm{AlCoCrFeMo}{ }_{0.5} \mathrm{NiSiTi}$, on the alumina substrate using a plasma spraying process, and the thickness of the coating layer is 160 microns. The oxidation test was performed on the corresponding coated alumina substrate in order to study oxidation properties. The obtained results demonstrated that both the coating layers demonstrated better oxidation resistance up to $1373 \mathrm{~K}$, which was confirmed by the weight gain values during oxide layer formation and weight gain of the oxide layer approached a constant level after about $50 \mathrm{~h}$ of the test, as shown in Fig. 9. The protective passive layer formation was detected by EDS mapping, where it was observed that the top protective layer belongs to Ti oxide, whereas the successive layer is composed of $\mathrm{Cr}$ oxide. However, the better oxidation resistance was not attributed to the $\mathrm{Ti}$ oxide layer instead, $\mathrm{Cr}$ presence in the alloy ascertained the oxidation protection.

\section{Concluding remarks and future directions}

The expanding applications of HEAs at high temperatures demand higher performance and high-temperature stability at extreme practical conditions. Oxidation behavior is one of the most crucial parameters to consider for hightemperature applications. This article reviews the limitedly available literature on the oxidation behavior of HEAs in 


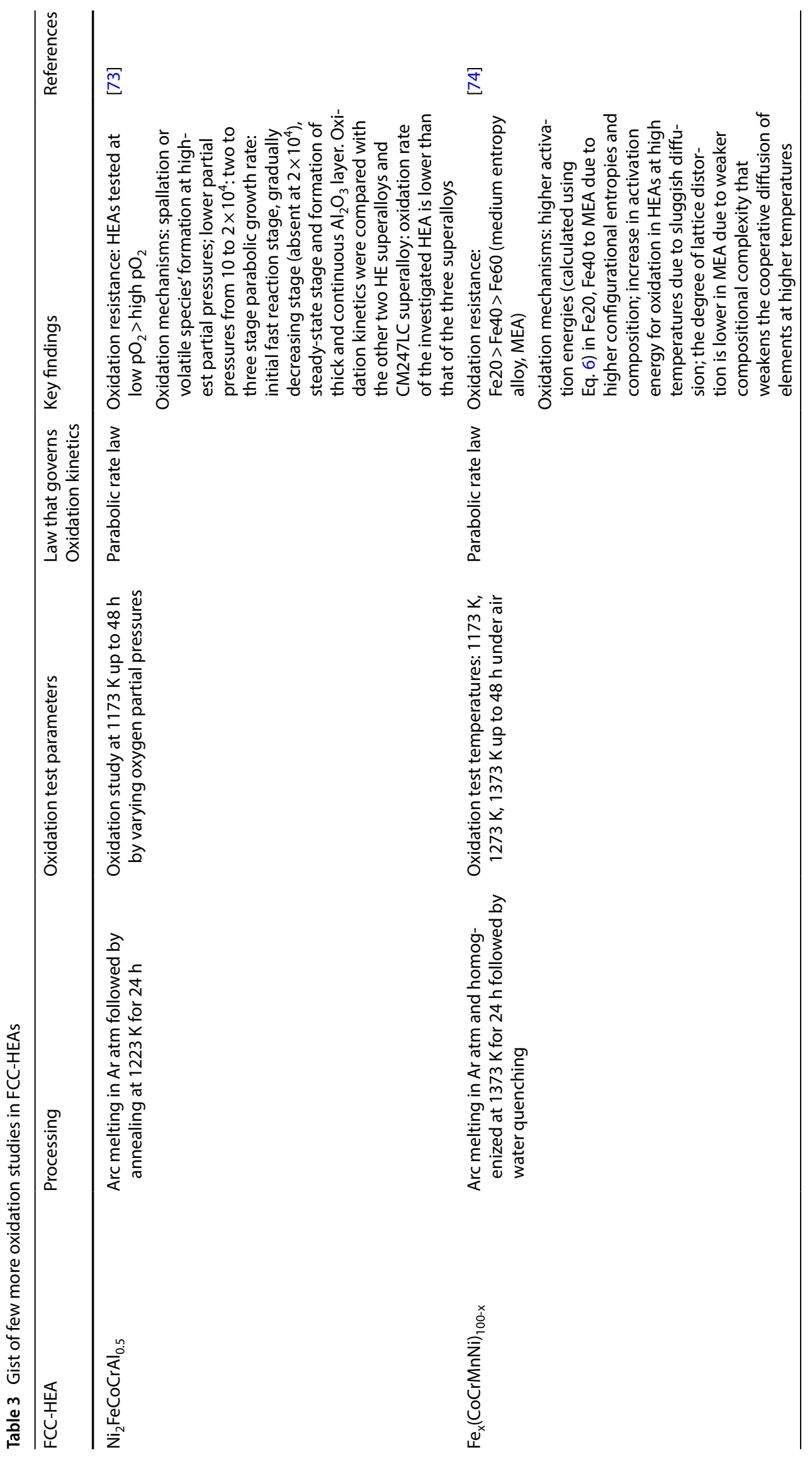




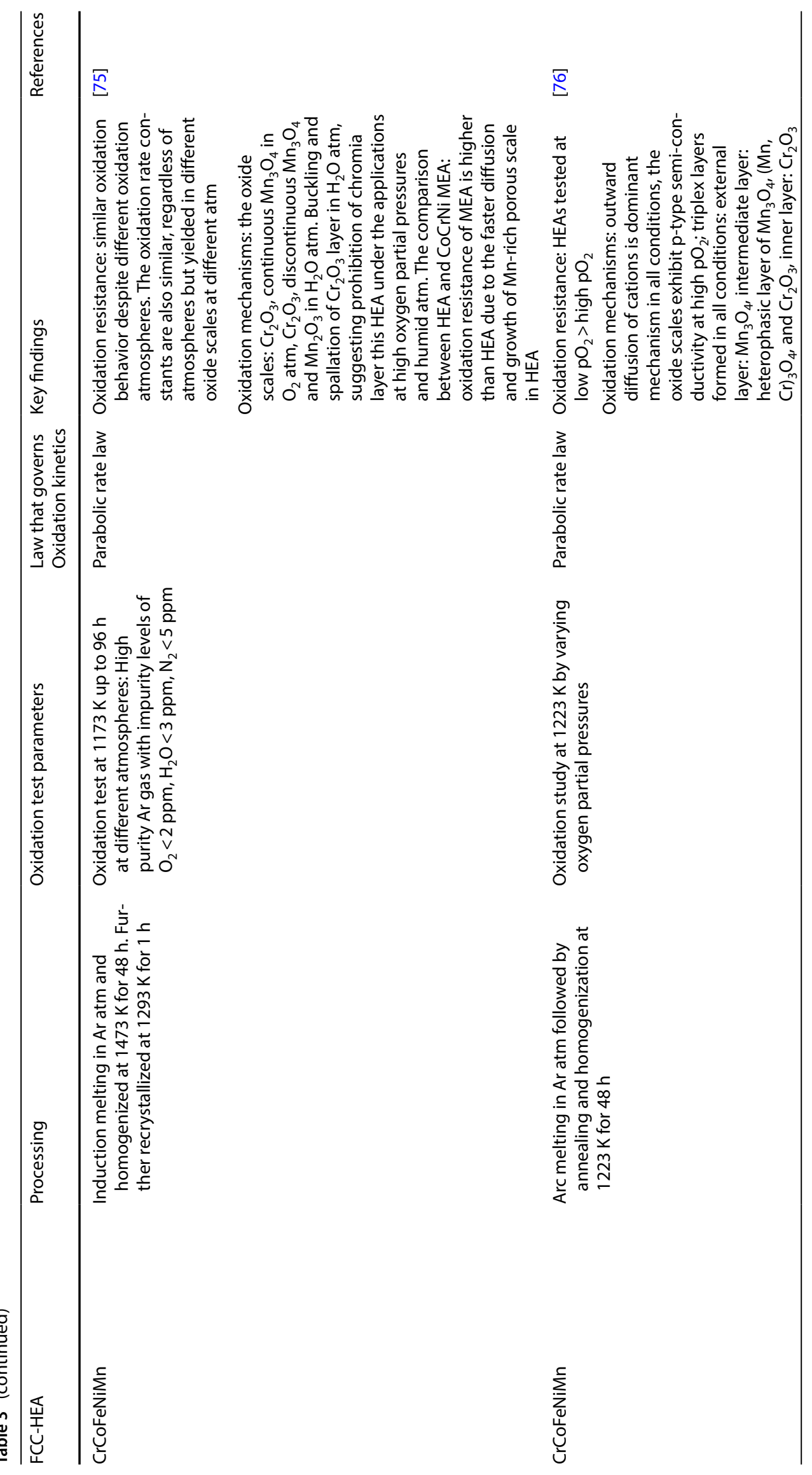

SN Applied Sciences 


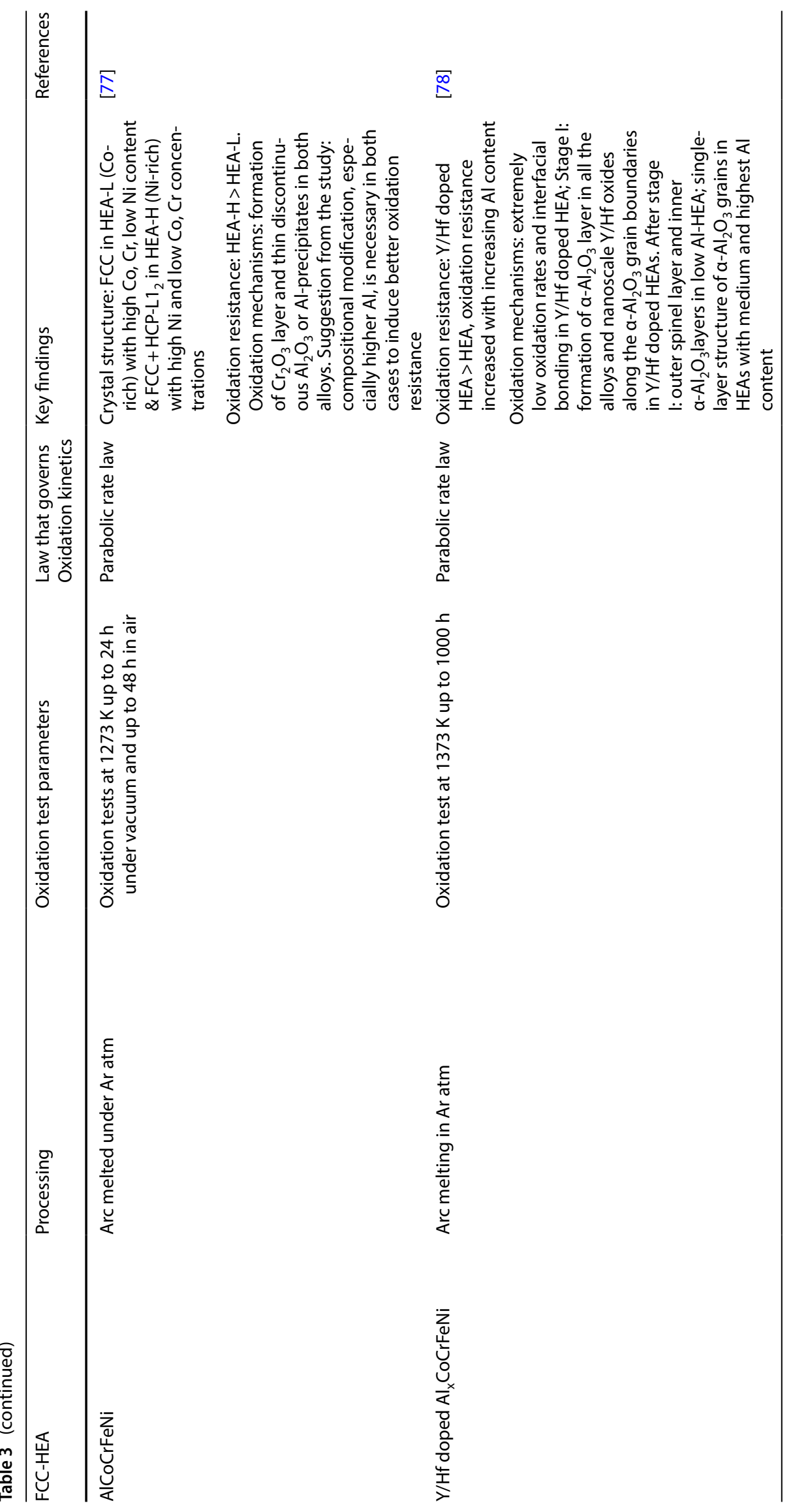




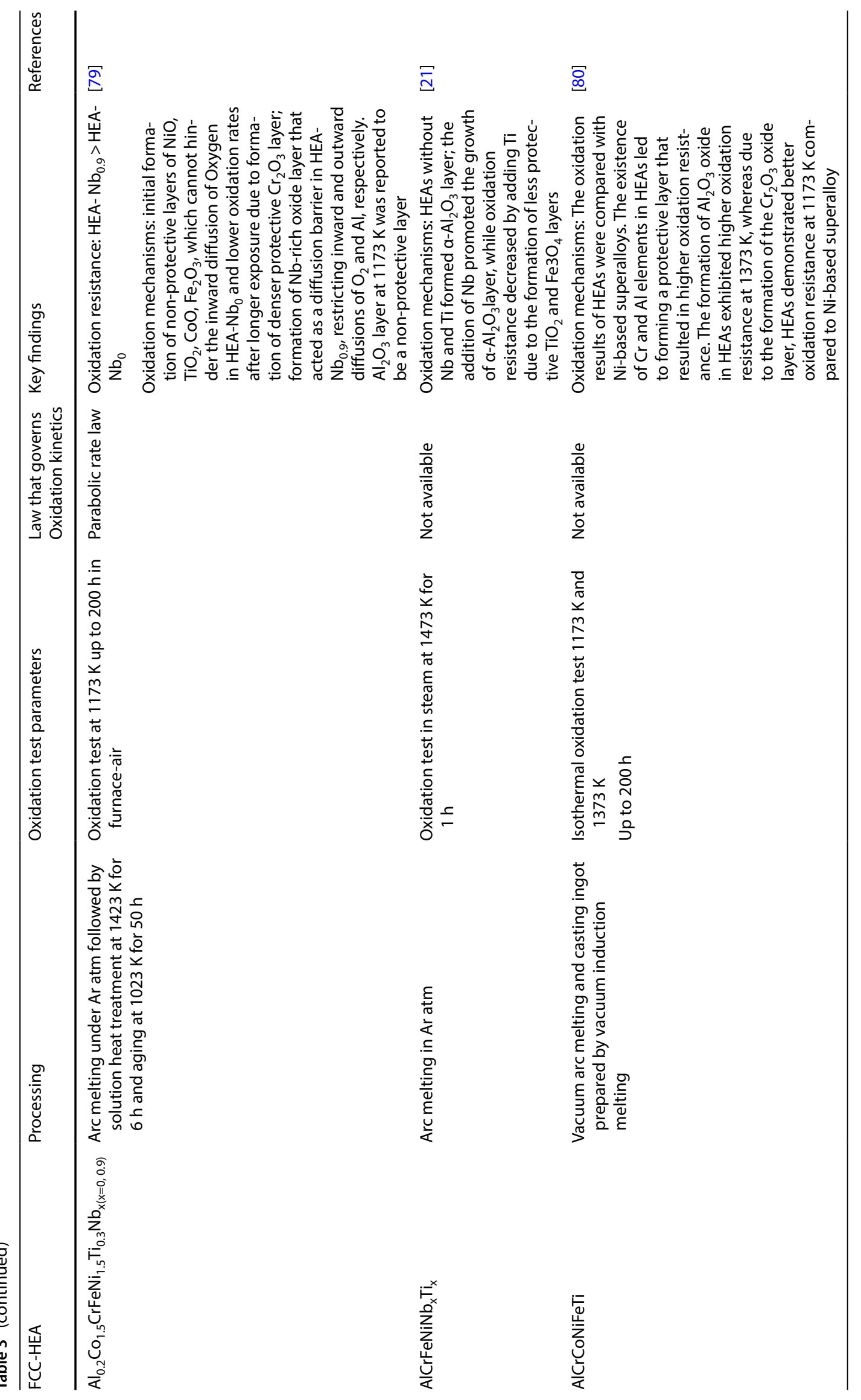

SN Applied Sciences

a SPRINGER NATURE journal 
order to enhance the scope and significance of oxidation study in HEAs. The trend of oxidation kinetics is similar between a few high-performance Nb alloys, AFA steels (alumina forming austenite), and HEAs. However, HEAs exhibit superior oxidation behavior and high-temperature stability over the other two alloys due to the four core effects of HEAs. The oxidation behavior of HEAs strongly influenced by the chemical composition and nature of formed oxide scales. Typically, HEAs that contain Al or $\mathrm{Cr}$ indeed evidence superior oxidation resistance up to
$1373 \mathrm{~K}$ inherently. The addition of a few more alloying elements further enhances the oxidation resistance of HEAs, which are suitable for high-performance applications. For example, the addition of $\mathrm{Ti}$ and $\mathrm{Si}$ to the $\mathrm{Al}_{0.5} \mathrm{CrNbMo} \mathrm{HEA}$ significantly enhances the oxidation resistance, whereas the addition of $V$ lowers the oxidation behavior of the HEA. The addition of $\mathrm{Si}$ up to $0.6 \%$ to the CoCrCuFeNi HEA favors the oxidation behavior. The oxidation behavior of HEAs strongly depends on the oxidation scales; the formation of protective $\mathrm{Al}_{2} \mathrm{O}_{3}$ and $\mathrm{Cr}_{2} \mathrm{O}_{3}$ scales highly enhances the
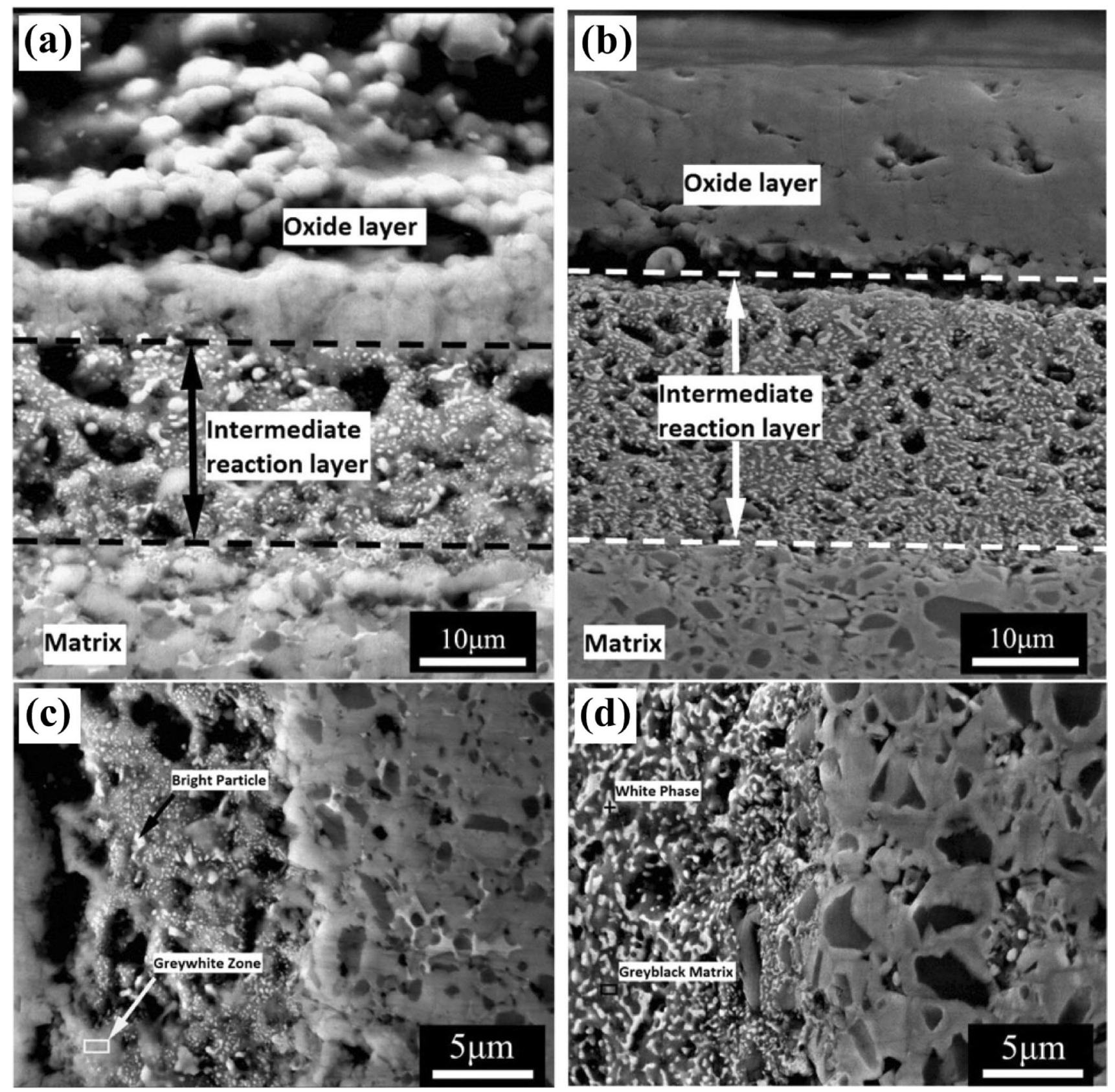

Fig. 8 Cross-sectional images of Ti $(C, N)$ cermet after isothermal oxidation at $1373 \mathrm{~K}$ for $4 \mathrm{~h}$ in static air with a Ni/Co bimetallic binder and $\mathbf{b}$ $\mathrm{HEA}$ (AICoCrFeNi) binder, and intermediate reaction layer formed on cermet $\mathbf{c}$ with $\mathrm{Ni} / \mathrm{Co}$ binder, $\mathbf{d}$ with $\mathrm{HEA}$ binder [82] 

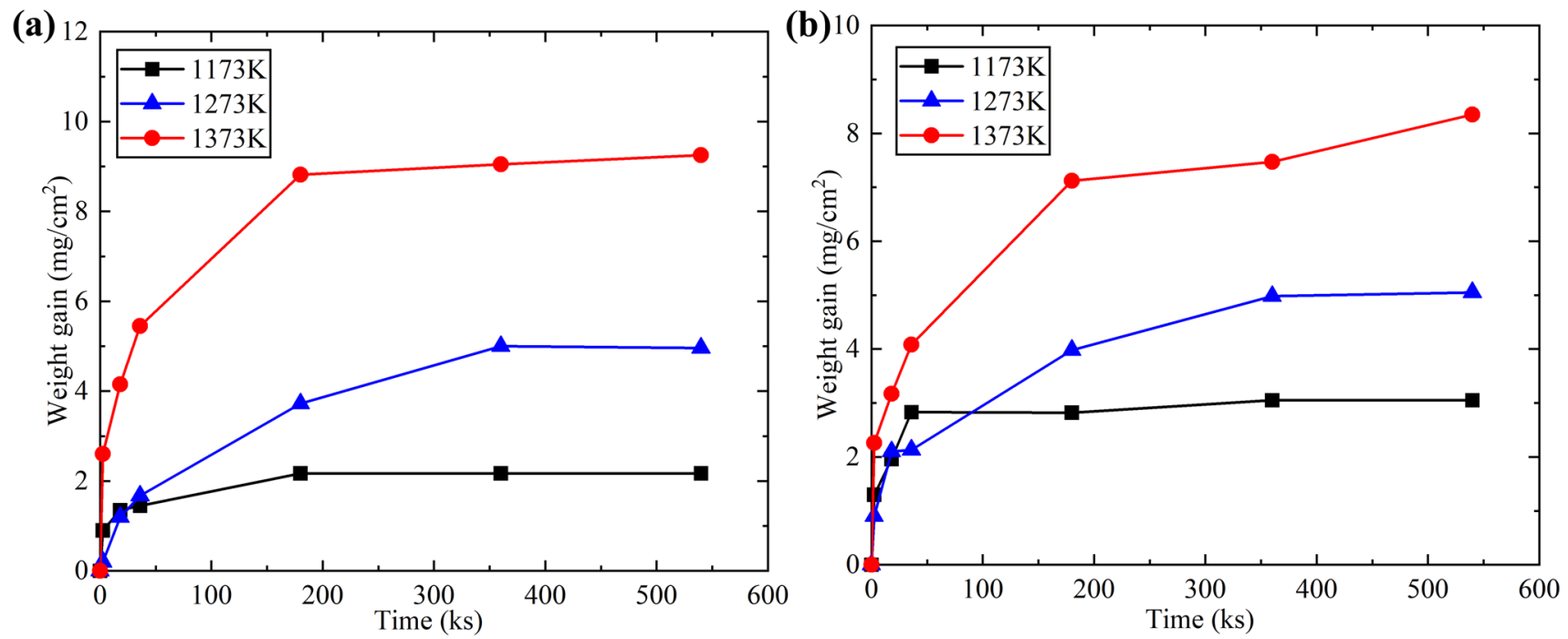

Fig. 9 Oxidation kinetics of a AlSiTiCrFeNiCoMo ${ }_{0.5}$ and $\mathbf{b}$ AlSiTiCrFeNiMo ${ }_{0.5}$ plasma-sprayed coatings [54]

oxidation behavior of HEAs, while it is vice versa with less protective oxides layers such as $\mathrm{TiO}_{2}, \mathrm{VO}_{x^{\prime}}, \mathrm{Fe}_{3} \mathrm{O}_{4}$. Thus, alloying additions that promote the homogenous growth of $\mathrm{Al}_{2} \mathrm{O}_{3}, \mathrm{Cr}_{2} \mathrm{O}_{3}$ layers, and which can abate the interdiffusion of oxygen and elements are beneficial for distinctive oxidation properties of HEAs.

Investigation of the oxidation behavior of HEAs is a budding research topic in the field of high-temperature materials and their applications. There is a much wider scope for extending oxidation studies in HEAs, as its research is very limited so far. The following are the few ideologies on expanding research on the oxidation behavior of HEAs:

1. In order to meet the demands of high-performance materials at extreme conditions such as high temperature, there is a necessity to investigate the oxidation properties of HEAs by altering alloying additions and tailoring the microstructure.

2. As the oxidation study of HEAs is a newly developing research field, comprehending and establishing fundamental theories/mechanisms involved in the oxidation behavior of HEAs is highly encouraged and deemed.

3. The most recent works on the oxidation behavior of HEAs studied by doping reactive elements such as $\mathrm{Y} /$ $\mathrm{Hf}$. There is a great need to investigate the oxidation behavior of HEAs by tailoring constitutive elements and their microstructure in this scenario.

4. The currently available works on oxidation behavior of HEAs mostly used HEAs processed by conventional methods such as arc melting and induction melting. The works can be extended to HEAs processed by other processing methods such as powder metallurgy techniques, additive manufacturing to understand the oxidation mechanisms that differ with processing.

5. The oxidation behavior of single-crystalline HEAs was not yet attempted. In order to investigate the oxidation behavior by eliminating the effect of grain boundaries, which often act as nucleation sites for crack, pits would be a standard and crucial contribution to the field of HEAs in high-temperature applications.

6. The Oxidation behavior of dual-phase HEAs such as eutectic HEAs is worthwhile to be originated and investigated.

7. Most of the available research on the oxidation study of HEAs thus far constrained to the limited compositions such as RHEA, $\mathrm{Al} / \mathrm{Cr}$ containing HEAs, and limited alloying elements. The field would be extended to wide compositional ranges to understand the effect of alloying additions and to elucidate the oxidation behavior with different HEAs extensively.

Author contributions BRA:Writing-original draft preparation, validation, conceptualization, methodology, Literature search and analysis, visualization, resources, project administration; SS: Writing-original draft preparation, validation, conceptualization, methodology, Literature search and analysis, visualization, resources; MT: Supervision, conceptualization, validation, resources, writing- review and editing; $A B$ : Supervision, conceptualization, validation, writing- review and editing.

Availability of data and material All data generated or analyzed during this study are included in this published article. 


\section{Compliance with ethical standards}

Conflicts of interest The authors declare that they have no known competing financial or non-financial interests that could have appeared to influence the work reported in this paper.

Ethical Approval This is the original manuscript that has neither been published nor under any considerations for the publication elsewhere. We do not have any conflicts of interest to disclose.

Open Access This article is licensed under a Creative Commons Attribution 4.0 International License, which permits use, sharing, adaptation, distribution and reproduction in any medium or format, as long as you give appropriate credit to the original author(s) and the source, provide a link to the Creative Commons licence, and indicate if changes were made. The images or other third party material in this article are included in the article's Creative Commons licence, unless indicated otherwise in a credit line to the material. If material is not included in the article's Creative Commons licence and your intended use is not permitted by statutory regulation or exceeds the permitted use, you will need to obtain permission directly from the copyright holder. To view a copy of this licence, visit http://creativecommons .org/licenses/by/4.0/.

\section{References}

1. Wang FJ, Zhang Y, Chen GL, Davies HA (2009) Cooling rate and size effect on the microstructure and mechanical properties of AICoCrFeNi high entropy alloy. J Eng Mater Technol 131:034501

2. Yeh JW, Chen SK, Lin SJ et al (2004) Nanostructured highentropy alloys with multiple principal elements: novel alloy design concepts and outcomes. Adv Eng Mater 6:299-303

3. Smith CS (1963) Four outstanding researchers in metallurgical history. American Society for Testing and Materials, Baltimore

4. Cantor B, Chang ITH, Knight P, Vincent AJB (2004) Microstructural development in equiatomic multicomponent alloys. Mater Sci Eng A 375-377:213-218

5. Deng Y, Tasan CC, Pradeep KG, Springer H, Kostka A, Raabe D (2015) Design of a twinning-induced plasticity high entropy alloy. Acta Mater 94:124-133

6. Greer AL (1993) Confusion by design. Nature 366:303-304

7. Zhou YJ, Zhang Y, Wang FJ, Wang YL, Chen GL (2008) Effect of $\mathrm{Cu}$ addition on the microstructure and mechanical properties of AlCoCrFeNiTi0.5 solid-solution alloy. J Alloys Compd 466:201-204

8. Chen YY, Duval T, Hung UD, Yeh JW, Shih HC (2005) Microstructure and electrochemical properties of high entropy alloys-a comparison with type-304 stainless steel. Corros Sci 47:2257-2279

9. Huang YS, Chen L, Lui HW, Cai MH, Yeh JW (2007) Microstructure, hardness, resistivity and thermal stability of sputtered oxide films of AlCoCrCu0.5NiFe high-entropy alloy. Mater Sci Eng A 457:77-83

10. Senkov ON, Senkova SV, Dimiduk DM, Woodward C, Miracle DB (2012) Oxidation behavior of a refractory NbCrMo0.5Ta0.5TiZr alloy. J Mater Sci 47:6522-6534

11. Chou YL, Wang YC, Yeh JW, Shih HC (2010) Pitting corrosion of the high-entropy alloy Co1.5CrFeNi1.5Ti0.5Mo0.1 in chloridecontaining sulphate solutions. Corros Sci 52:3481-3491

12. Gludovatz B, Hohenwarter A, Catoor D, Chang EH, George EP, Ritchie R (2014) A fracture-resistant high-entropy alloy for cryogenic applications. Science 345:1153-1158
13. Wen LH, Kou HC, Li JS, Chang H, Xue XY, Zhou L (2009) Effect of aging temperature on microstructure and properties of $\mathrm{AlCo}$ CrCuFeNi high-entropy alloy. Intermetallics 17:266-269

14. Senkov ON, Wilks GB, Scott JM, Miracle DB (2011) Mechanical properties of Nb25Mo25Ta25W25 and V20Nb20Mo20Ta20W20 refractory high entropy alloys. Intermetallics 19:698-706

15. Zhu JM, Fu HM, Zhang HF, Wang AM, Li H, Hu ZQ (2010) Synthesis and properties of multiprincipal component AlCoCrFeNiSix alloys. Mater Sci Eng A 527:27-28

16. Tsai MH, Yeh JW (2014) High-entropy alloys: a critical review. Mater Res Lett 2:107-123

17. Kim YK, Joo YA, Kim HS, Lee KA (2018) High temperature oxidation behavior of $\mathrm{Cr}-\mathrm{Mn}$-Fe-Co-Ni high entropy alloy. Intermetallics 98:45-53

18. Liu YX, Cheng CQ, Shang JL, Wang R, Li P, Zhao J (2015) Oxidation behavior of high-entropy alloys AlxCoCrFeNi $(x=0.15,04)$ in supercritical water and comparison with HR3C steel. Trans Nonferrous Met Soc China 25:1341-1351

19. Shaik S, Kumar A, Chopkar M, Basu A (2020) Oxidation study of CoCrCuFeNiSix high entropy alloys. Mater Res Exp 7:016532

20. Birks N, Meier H, Pettit FS (2016) Introduction to the hightemperature oxidation of metals. Cambridge University Press, Cambridge

21. Shi H, Tang C, Jianu A et al (2020) Oxidation behavior and microstructure evolution of alumina-forming austenitic and high entropy alloys in steam environment at $1200^{\circ} \mathrm{C}$. Corros Sci 170:108654

22. Nong Z-S, Lei Y-N, Zhu J-C (2018) Wear and oxidation resistances of AICrFeNiTi-based high entropy alloys. Intermetallics 101:144-151

23. Giggins CS, Pettit FS (1971) Oxidation of Ni-Cr-Al Alloys Between $1000^{\circ}$ and $1200^{\circ} \mathrm{C}$. J Electrochem Soc 118:1782-1790

24. Wallwork GR, Hed AZ (1971) Some limiting factors in the use of alloys at high temperatures. Oxid Met 3:171-184

25. Kai W, Cheng FP, Liao CY, Li CC, Huang RT, Kai JJ (2018) The oxidation behavior of the quinary $\mathrm{FeCoNiCrSix} \mathrm{high-entropy}$ alloys. Mater Chem Phys 210:362-369

26. Gorr B, Mueller F, Christ H-J et al (2016) High temperature oxidation behavior of an equimolar refractory metal-based alloy 20Nb-20Mo-20Cr-20Ti-20Al with and without Si addition. J Alloys Compd 688:468-477

27. Ogura M, Fukushima T, Zeller R, Dederichs PH (2017) Structure of the high-entropy alloy AlxCrFeCoNi: fcc versus bcc. J Alloys Compd 715:454-459

28. Chattopadhyay K, Mitra R, Ray KK (2008) Nonisothermal and isothermal oxidation behavior of $\mathrm{Nb}-\mathrm{Si}-\mathrm{Mo}$ alloys. Metall Mater Trans A 39:577-592

29. Murayama Y, Hanada S (2002) High temperature strength, fracture toughness and oxidation resistance of $\mathrm{Nb}-\mathrm{Si}-\mathrm{Al}-\mathrm{Ti}$ multiphase alloys. Sci Technol Adv Mater 3:145-156

30. Perkins RA, Chiang KT, Meier GH (1988) Formation of alumina on Nb-Al alloys. Scr Metall 22:419-424

31. Wang R, Tang Y, Li S et al (2020) Effect of lattice distortion on the diffusion behavior of high-entropy alloys. J Alloys Compd $825: 154099$

32. Love GR (1964) Dislocation pipe diffusion. Acta Metall 12:731-737

33. Liu CM, Wang HM, Zhang SQ, Tang HB, Zhang AL (2014) Microstructure and oxidation behavior of new refractory high entropy alloys. J Alloys Compd 583:162-169

34. Yin L, Yi DQ, Xiao LR, Yang L, Liu HQ (2003) Research progress in high temperature oxidation resistance of $\mathrm{Nb}$ and $\mathrm{Nb}$-based alloys. Mater Prot 36:4-8

35. Geng J, Tsakiropoulos P, Shao GS (2006) Oxidation of Nb-Si$\mathrm{Cr}-\mathrm{Al}$ in situ composites with $\mathrm{Mo}, \mathrm{Ti}$ and $\mathrm{Hf}$ additions. Mater Sci Eng A 441:26-38 
36. Yi DQ, Li D, Liu HQ, Wu CP, Zhou HM (2007) Microstructure and oxidation behavior of mechanically alloyed $\mathrm{Nb}$-Based multiphase superalloy. J Iron Steel Res Int 14:1-6

37. Heilmaier M, Krüger M, Saage $\mathrm{H}$ et al (2009) Metallic materials for structural applications beyond nickel-based superalloys. JOM 61:61-67

38. Durcham R, Gleeson B, Young DJ (1998) Silicon contamination effects in the oxidation of carbide-containing cobaltchromium alloys. Mater Corros 49:855-863

39. Wang S, Wu Y, Gesmundo F, Niu Y (2008) The effect of Si additions on the high-temperature oxidation of a ternary $\mathrm{Ni}-10 \mathrm{Cr}-$ 4AI Alloy in 1 ATM O2 AT 900-1000 ${ }^{\circ} \mathrm{C}$. Oxid Met 69:299-315

40. Gorr B, Azim M, Christ H-J, Mueller T, Schliephake D, Heilmaier $M(2015)$ Phase equilibria, microstructure, and high temperature oxidation resistance of novel refractory high-entropy alloys. J Alloys Compd 624:270-278

41. Becker S, Rahmel A, Schorr M, Schütze M (1992) Mechanism of isothermal oxidation of the intermetallic TiAl and of TiAl alloys. Oxid Met 38:425-464

42. Zhang P, Li Y, Chen Z, Zhang J, Shen B (2019) Oxidation response of a vacuum arc melted NbZrTiCrAl refractory high entropy alloy at $800-1200^{\circ} \mathrm{C}$. Vacuum 162:20-27

43. Li L-C, Li M-X, Liu M et al (2020) Enhanced oxidation resistance of MoTaTiCrAl high entropy alloys by removal of Al. Sci China Mater. https://doi.org/10.1007/s40843-020-1332-2

44. Butler TM, Alfano JP, Martens RL, Weaver ML (2015) High-temperature oxidation behavior of $\mathrm{Al}-\mathrm{Co}-\mathrm{CrNi}$-(Fe or $\mathrm{Si}$ ) multicomponent high-entropy alloys. JOM 67:246-259

45. Chang CH, Titus MS, Yeh JW (2018) Oxidation behavior between 700 and $1300{ }^{\circ} \mathrm{C}$ of refractory TiZrNbHfTa high-entropy alloys containing aluminum. Adv Eng Mater 20:1700948

46. Lo KC, Chang YJ, Murakami H, Yeh JW, Yeh AC (2019) An oxidation resistant refractory high entropy alloy protected by $\mathrm{CrTaO} 4$ based oxide. Sci Rep 9:7266

47. Gorr B, Müller F, Azim M et al (2017) High-temperature oxidation behavior of refractory high-entropy alloys: effect of alloy composition. Oxid Met 88:339-349

48. Erdogan A, Doleker KM, Zaytin S (2019) Effect of Al and Ti on high-temperature oxidation behavior of $\mathrm{CoCrFeNi-based} \mathrm{high-}$ entropy alloys. JOM 71:3499-3510

49. Müller F, Gorr B, Christ H-J, Chen H, Kauffmann A, Heilmaier M (2017) Effect of microalloying with silicon on high temperature oxidation resistance of novel refractory high-entropy alloy TaMo-Cr-Ti-Al. Mater High Temp 35:168-176

50. Jayaraj J, Thirathipviwat P, Han J, Gebert A (2018) Microstructure, mechanical and thermal oxidation behavior of AINbTiZr high entropy alloy. Intermetallics 100:9-19

51. Yurchenko N, Panina E, Zherebstov S, Salishchev G, Stepanov $\mathrm{N}$ (2018) Oxidation behavior of refractory AINbTiVZr0.25 highentropy alloy. Materials (Basel) 11:2526

52. Wang S, Chen Z, Zhang P, Zhang K, Chen CL, Shen BL (2019) Influence of Al content on high temperature oxidation behavior of AlxCoCrFeNiTi05 high entropy alloys. Vacuum 163:263-268

53. Zhang R, Meng J, Han J, Tulugan K, Zhang R (2021) Oxidation resistance properties of refractory high-entropy alloys with varied AlxCrTiMo content. Met Corros 56:3551-3561

54. Huang PK, Yeh JW, Shun TT, Chen SK (2004) Multi-principal-element alloys with improved oxidation and wear resistance for thermal spray coating. Adv Eng Mater 6:74-78

55. Jw YEH, Lin SJ, Chin TS et al (2004) Formation of simple crystal structures in solid-solution alloys with multi-principal metallic elements. Metall Mater Trans A 35:2533-2536

56. Tong CJ, Chen YL, Yeh JW et al (2005) Microstructure characterization of AlxCoCrCuFeNi high-entropy alloy system with multiprincipal elements. Metall Mater Trans A 36:881-893
57. Fj WANG, Zhang Y, Chen GL (2009) Atomic packing efficiency and phase transition in a high entropy alloy. J Alloys Compd 478:321-324

58. Chen L, Zhou Z, Tan Z et al (2018) High temperature oxidation

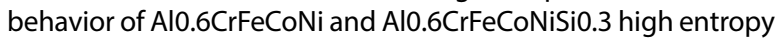
alloys. J Alloys Compd 764:845-852

59. Laplanche G, Volkert UF, Eggeler G, George EP (2016) Oxidation behavior of the $\mathrm{CrMnFeCoNi}$ high-entropy alloy. Oxid Met 85:629-645

60. Jackson PRS, Wallwork GR (1984) High temperature oxidation of iron-manganese-aluminum based alloys. Oxid Met 21:135-170

61. Duh JG, Lee JW, Wang CJ (1988) Microstructural development in the oxidation-induced phase transformation of $\mathrm{Fe}-\mathrm{Al}-\mathrm{Cr}-\mathrm{Mn}-$ alloys. J Mater Sci 23:2649-2660

62. Duh JG, Wang CJ (1990) High tempeature oxidation of Fe-31 Mn-9AI-xCr-0.87C alloys ( $x=0,3$ and 6). J Mater Sci 25:268-276

63. Liu JY, Chang SC (1997) The oxidation and carburization of Fe$\mathrm{Mn}-\mathrm{Al}$ alloys in a carbon-containing atmosphere. Corros Sci 39:1021-1035

64. Wild RK (1977) High temperature oxidation of austenitic stainless steel in low oxygen pressure. Corros Sci 17(87-93):95-104

65. Stott FH, Wei FI, Enahoro CA (1989) The influence of manganese on the High-temperature oxidation of iron-chromium alloys. Mater Corros 40:198-205

66. Marasco AL, Young DJ (1991) The oxidation of Iron-ChromiumManganese alloys at $900^{\circ} \mathrm{C}$. Oxid Met 36:157-174

67. Douglass DL, Gesmundo F, de Asmundis C (1986) The air oxidation of an austenitic Fe- $\mathrm{Mn}-\mathrm{Cr}$ stainless steel for fusion-reactor applications. Oxid Met 25:235-268

68. Douglass DL, Rizzo-Assuncao F (1988) The oxidation of Fe19.6Cr-15.1Mn stainless steel. Oxid. Met. 29:271-287

69. Croll JE, Wallwork GR (1972) The high-temperature oxidation of iron-chromium-nickel alloys containing $0-30 \%$ chromium. Oxid Met 4:121-140

70. Kai W, Cheng FP, Lin YR et al (2020) The oxidation behavior of $\mathrm{Ni2} F \mathrm{CeC}$ CrAlx high-entropy alloys in dry air. J Alloys Compd 836:155518

71. Gordon RH, Tylczak J, Carney C (2015) Oxidation of CoCrFeMnNi high entropy alloys. JOM 67:2326-2339

72. Stott FH, Wei FI, Enahoro CA (1989) The influence of manganese on the High-temperature oxidation of iron-chromium alloys. Met Corros 40:198-205

73. Kai W, Cheng FP, Chien FC et al (2019) The oxidation behavior of a Ni2FeCoCrAl0.5 high-entropy superalloy in O2- containing environments. Corros. Sci. 158:108093

74. Agustianingrum MP, Latief FH, Park N, Lee U (2020) Thermal oxidation characteristics of Fex(CoCrMnNi) $100-x$ medium and high-entropy alloys. Intermetallics 120:106757

75. Schreb CS, Schulz W, Schneider M, Karafiludis S, Laplanche G (2020) High-Temperature oxidation in dry and humid atmospheres of the equiatomic $\mathrm{CrMnFeCoNi}$ and $\mathrm{CrCoNi}$ high- and medium-entropy alloys. Oxid Met. https://doi.org/10.1007/ s11085-020-10014-7

76. Kai W, Li CC, Cheng FP et al (2016) The oxidation behavior of an equimolar FeCoNiCrMn high-entropy alloy at $9500^{\circ} \mathrm{C}$ in various oxygen-containing atmospheres. Corros Sci 108:209-214

77. Gawel R, Rogal L, Dabek J, W-BaniaPrzybylski MK (2021) High temperature oxidation behaviour of non-equimolar AlCoCrFeNi high entropy alloys. Vacuum 184:109969

78. Lu J, Chen Y, Zhang H et al (2020) Effect of Al content on the oxidation behavior of $\mathrm{Y} / \mathrm{Hf}$-doped $\mathrm{AlCoCrFeNi}$ high-entropy alloy. Corros Sci 170:108691

79. Yang J-J, Kuo C-M, Lin P-T et al (2020) Improvement in oxidation behavior of Al0.2Co1.5CrFeNi1.5Ti0.3 highentropy superalloys by minor $\mathrm{Nb}$ addition. J Alloys Compd 825:153983 
80. Tsao TK, Yeh AC, Kuo CM, Murakami H (2016) High temperature oxidation and corrosion properties of high entropy superalloys. Entropy 18:62

81. Zhu G, Liu Y, Ye J (2013) Fabrication and properties of Ti(C, N)based cermets with multi-component AlCoCrFeNi high-entropy alloys binder. Mater Lett 113:80-82
82. Zhu G, Liu Y, Ye J (2014) Early high-temperature oxidation behavior of Ti(C, N)-based cer-mets with multi-component AlCoCrFeNi high-entropy alloy binder. Int J Refract Met Hard Mater 44:35-41

Publisher's Note Springer Nature remains neutral with regard to jurisdictional claims in published maps and institutional affiliations. 